\title{
Novel reversibly switchable fluorescent molecular systems based on metallacarborane-perylenediimide conjugates
}

Laura Parejo, ${ }^{[\mathrm{a}] \dagger}$ Mahdi Chaari, ${ }^{[\mathrm{b}] \dagger}$ Sara Santiago, ${ }^{[\mathrm{a}]}$ Gonzalo Guirado, ${ }^{[\mathrm{a}]}$ Francesc Teixidor, ${ }^{[\mathrm{b}]}$ Rosario Núñez, ${ }^{*[b]}$ and Jordi Hernando ${ }^{*[a]}$

[a] L. Parejo, S. Santiago, Dr. G. Guirado, Dr. J. Hernando

Departament de Química

Universitat Autònoma de Barcelona

E-08193 Bellaterra (Barcelona), Spain

jordi.hernando@uab.es

[b] Dr. M. Chaari, Prof. F. Teixidor, Dr. R. Nuñez

Institut de Ciencia de Materials de Barcelona (ICMAB-CSIC)

Campus de la UAB, E-08193 Bellaterra (Barcelona), Spain

rosario@icmab.es

$\dagger$ These authors contributed equally to this work

\begin{abstract}
Icosahedral metallacarboranes are $\theta$-shaped anionic molecules in which two icosahedra share one vertex that is a metal center. The most remarkable of these compounds is the anionic cobalt-based metallacarborane $\left[\mathrm{Co}\left(\mathrm{C}_{2} \mathrm{~B}_{9} \mathrm{H}_{11}\right)_{2}\right]^{-}$, whose oxidation-reduction processes occur via an outer sphere electron process. This, along with its low density negative charge, makes $\left[\mathrm{Co}\left(\mathrm{C}_{2} \mathrm{~B}_{9} \mathrm{H}_{11}\right)_{2}\right]^{-}$very appealing to participate in electron-transfer processes. In this work, $\left[\mathrm{Co}\left(\mathrm{C}_{2} \mathrm{~B}_{9} \mathrm{H}_{11}\right)_{2}\right]^{-}$is tethered to a perylenediimide dye to produce the first examples of switchable luminescent molecules and materials based on metallacarboranes. In particular, the electronic communication of $\left[\mathrm{Co}\left(\mathrm{C}_{2} \mathrm{~B}_{9} \mathrm{H}_{11}\right)_{2}\right]^{-}$with the appended chromophore unit in these compounds can be regulated upon application of redox stimuli, which allows the reversible modulation of the emitted fluorescence. As such, they behave as electrochemically-controlled
\end{abstract}


fluorescent molecular switches in solution, which surpass the performance of previous systems based on conjugates of perylendiimides with ferrocene. Remarkably, they can form gels by treatment with appropriate mixtures of organic solvents, which result from the selfassembly of the cobaltabisdicarbollide-perylendiimide conjugates into $1 \mathrm{D}$ nanostructures. The interplay between dye $\pi$-stacking and metallacarborane electronic and steric interactions ultimately governs the supramolecular arrangement in these materials, which for one of the compounds prepared allows preserving the luminescent behavior in the gel state.

\section{Introduction}

Carboranes and their derivatives are polyhedral boron-based clusters that have been proposed for a variety of applications, ${ }^{[1]}$ ranging from biomedicine ${ }^{[2]}$ to catalysis ${ }^{[3]}$ and materials science. $^{[4]}$ Among them, the use of these systems for the development of luminescent molecules and materials is raising increasing interest. ${ }^{[5]}$ To date most efforts in this field have been focused on the synthesis of carborane-emitter conjugates, where two main features of boron clusters are generally exploited: (a) their 3D bulk geometry, which allows spatial control of interchromophoric interactions between attached fluorophores in solution (e.g. excited-state energy transfer) $^{[6]}$ and enables aggregation-induced emission (AIE) in the solidstate; ${ }^{[7]}$ and (b) their electron-withdrawing (e.g. 1,2-dicarba-closo-carborane) or electrondonating (e.g. 7,8-dicarba-nido-dodecaborane) nature, which can be utilized to modulate the emission from nearby fluorophores via photoinduced charge transfer (CT) and, by taking advantage of the steric congestion around the carborane motifs, to generate intramolecular CT states displaying intense AIE luminescence upon aggregation. ${ }^{[8]}$

The emission from these AIE-active, CT-based carborane-emitter conjugates is sensitive to external stimuli that alter molecular packing (e.g. mechanical forces, temperature, chemical 
environment), and can be used for the preparation of smart materials. ${ }^{[8 c-j]}$ However, attempts to provide further functionality to these systems by reversibly switching the electronic communication between fluorophores and boron clusters have not been reported. To reach this goal, herein we decided to replace the common metal-free 1,2-dicarba-closo-dodecaborane employed in most studies with a cobalt-based metallacarborane showing a much richer electrochemical behavior. In particular, our attention focused on the metallacarborane anion cobaltabisdicarbollide $\left(\left[3,3 \text { '- } \mathrm{Co}\left(\mathrm{C}_{2} \mathrm{~B}_{9} \mathrm{H}_{11}\right)_{2}\right]^{-}\right.$, more commonly known as $\left.\mathrm{COSAN}\right)$, a boron cluster-based complex in which two dicarbollide ligands $\left(\left[\mathrm{C}_{2} \mathrm{~B}_{9} \mathrm{H}_{11}\right]^{2-}\right)$ are coordinated $\eta^{5}$ to a Co(III) center. ${ }^{[1,9]}$ Owing to the presence of the metal, this complex and its derivatives display several well-studied reversible waves under cyclic voltammetry conditions arising from the oxidation $(\mathrm{Co}(\mathrm{III}) / \mathrm{Co}(\mathrm{IV}))$ and reduction $(\mathrm{Co}(\mathrm{III}) / \mathrm{Co}(\mathrm{II})$ and $\mathrm{Co}(\mathrm{II}) / \mathrm{Co}(\mathrm{I}))$ of the cobalt ion. ${ }^{[5 a, 10]}$ Also, the COSAN anion presents other remarkable features, such as exceptional chemical stability, ${ }^{[1,4 a, 11]}$ low charge density and weak coordination capacity, ${ }^{[12]}$ and hydrophobicity. ${ }^{[13]}$ The latter makes the protonated form and sodium salts of COSAN highly amphiphilic, which accounts for their good solubility both in water and organic solvents, as well as for their capacity to self-assemble into micelles and monolayer vesicles in aqueous media. ${ }^{[14]}$ Because of this combination of properties, COSAN has been efficiently linked to the surface of platforms of different nature, such as dendrimers, ${ }^{[15]}$ octasilsesquioxanes, ${ }^{[16]}$ $\mathrm{TiO}_{2}{ }^{[17]}$ and polymeric nanoparticles, ${ }^{[18]} \mathrm{SWCNTs}^{[19]}$ or graphene oxide, ${ }^{[20]}$ giving rise to materials with enhanced solubility, dispersability, thermal stability, and electrochemical features.

By contrast, the utilization of COSAN and other metallacarboranes to the development of emissive systems has been rather scarce. ${ }^{[5,6 e]}$ Mainly, we ${ }^{[21]}$ and others ${ }^{[22]}$ have reported the synthesis of several conjugates of COSAN derivatives with organic fluorescent dyes (e.g. porphyrin, ${ }^{[22 \mathrm{a}-\mathrm{c}]}$ phtalocyanine, ${ }^{[22 \mathrm{~d}-\mathrm{e}]}$ fluorescein,${ }^{[2 \mathrm{f}]}$ BODIPY $\left.{ }^{[21 \mathrm{~b}]}\right)$, essentially aiming to 
improve their solubility, cellular uptake and intracellular boron release for theranostic applications that combine fluorescence diagnosis with anticancer boron neutron capture therapy. In none of these cases, however, the photoluminescence properties of the fluorophores benefited from the presence of nearby metallacarborane clusters, which mainly cause a decrease of the fluorescence efficiency, ${ }^{[21,22]}$ and, to the best of our knowledge, no externally-controlled switchable fluorescence behaviour was described for any of them. In this work we aimed to take a step beyond and exploit the redox versatility of COSAN to derive for the first time electrochemically-responsive fluorescent compounds based on (metalla)carboranes. It is important to keep in mind that to achieve redox-controlled fluorescence switching in metallacarborane-fluorophore systems is not straightforward, but it requires wise selection of their composition and structure to warrant: (a) tunable excited-state interaction between the dye and the metallacarborane as to selectively quench fluorescence in one of the redox states of the compound; and (b) selective access to the redox switching of the metallocarborane without affecting the fluorophore. In addition, by capitalizing on the selfassembly capacity of COSAN, we explored the use of these compounds for the preparation of solid materials with enhanced luminescence. Bearing these objectives in mind, we designed conjugates $\mathbf{1}$ and $\mathbf{2}$, which are a dyad and a triad of COSAN with a perylenediimide (PDI) dye (Figure 1). PDIs are well-known chromophores presenting outstanding absorption and emission properties as well as high thermal and photochemical stability. ${ }^{[23]}$ In addition, they present two other advantageous features that are of special relevance for this work: (a) PDIs are good photoexcited electron acceptors, which enables light-induced charge transfer processes with other close-by molecular components; ${ }^{[23,24]}$ and (b) PDIs present a large tendency to self-assemble via $\pi-\pi$ and solvophobic interactions to generate supramolecular architectures. $^{[23,25]}$ 

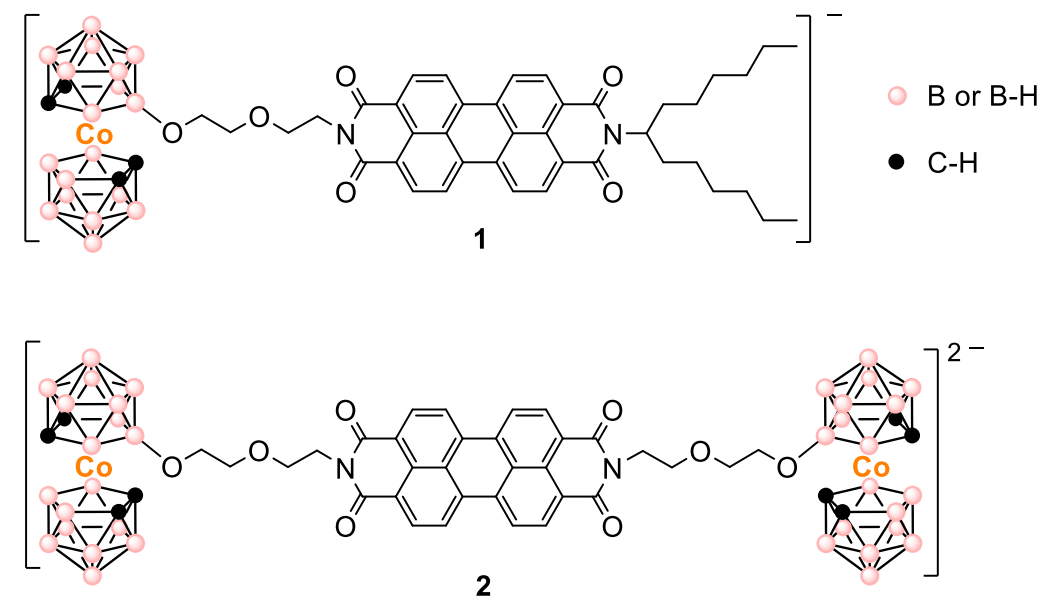

Figure 1. Structures of COSAN-PDI dyad 1 and triad 2.

\section{Results and Discussion}

\section{Synthesis and structural characterization}

The COSAN derivative $[\mathrm{H}]\left[8-\mathrm{NH}_{2}-\mathrm{C}_{4} \mathrm{H}_{8} \mathrm{O}_{2}-3,3\right.$ ' $\left.-\mathrm{Co}\left(1,2-\mathrm{C}_{2} \mathrm{~B}_{9} \mathrm{H}_{10}\right)\left(1^{\prime}, 2^{\prime}-\mathrm{C}_{2} \mathrm{~B}_{9} \mathrm{H}_{11}\right)\right]$ (3) was the metallacarborane building block selected for the preparation of $\mathbf{1}$ and $\mathbf{2}$ (Scheme 1). Different factors accounted for this choice. First, its 2-(2-aminoethoxy)ethoxy pending chain should warrant facile conjugation to PDI fluorophores by exploiting the well-known reaction between terminal amino groups and perylene anhydrides. ${ }^{[23,26]}$ Second, the resulting oligooxyethylene tether linking the metallacarborane and PDI units in $\mathbf{1}$ and $\mathbf{2}$ should allow preserving the redox properties of the COSAN core ${ }^{[5 \mathrm{a}]}$ while enabling photoinduced charge transfer with the fluorophore, as previously suggested for similar conjugates with other emitters. ${ }^{[21 \mathrm{~b}, \mathrm{c}]}$ Finally, 3 could be easily obtained from its precursor [3,3'- $\mathrm{Co}\left(8-\mathrm{C}_{4} \mathrm{H}_{8} \mathrm{O}_{2}-1,2-\right.$ $\left.\left.\mathrm{C}_{2} \mathrm{~B}_{9} \mathrm{H}_{10}\right)\left(1^{\prime}, 2^{\prime}-\mathrm{C}_{2} \mathrm{~B}_{9} \mathrm{H}_{11}\right)\right](6),{ }^{[27]}$ for which we slightly modified the conditions previously described for the nucleophilic oxonium ring-opening reaction with $\mathrm{NH}_{3}$ (Scheme $\mathrm{S} 1$, Supporting Information). ${ }^{[28]}$ 


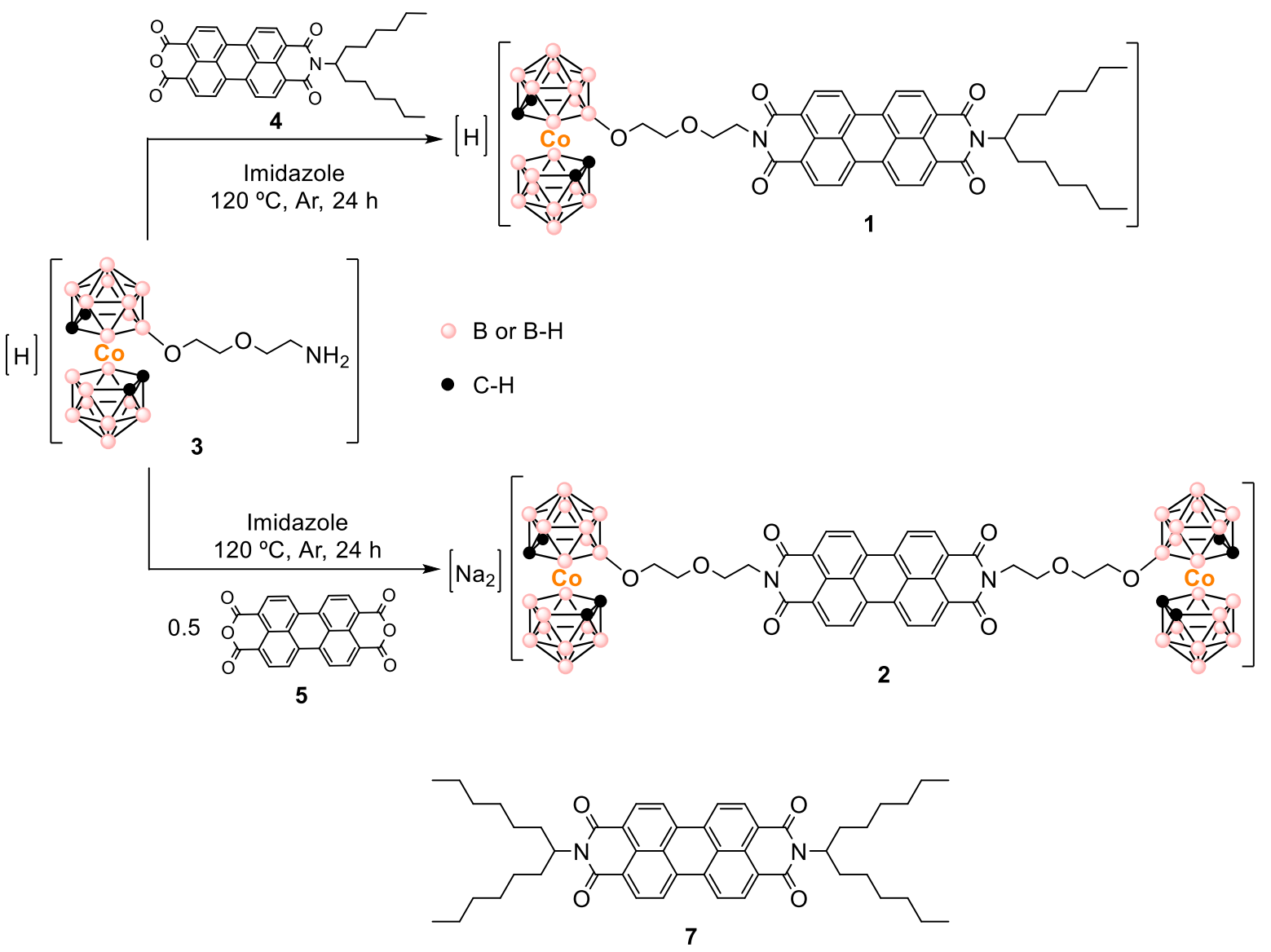

Scheme 1. Synthetic procedure for the synthesis of COSAN-PDI conjugates $\mathbf{1}$ and $\mathbf{2}$. The structure of PDI reference fluorophore 7 is also given.

For the synthesis of COSAN-PDI dyad 1, we first prepared perylene derivative 4 following literature procedures (Scheme S2, Supporting Information). ${ }^{[26]}$ Then, the stoichiometric reaction between $\mathbf{4}$ and COSAN derivative $\mathbf{3}$ was conducted in imidazole at 120 ${ }^{\circ} \mathrm{C}$ for $24 \mathrm{~h}$, which led to the formation of the protonated form of $\mathbf{1}$ in high yield (92\%) (Scheme 1). Similarly, the reaction of commercial perylene-3,4,9-10 tetracarboxylic anhydride (5) and $\mathbf{3}$ applying the same conditions as for compound $\mathbf{1}$ furnished COSAN-PDI triad 2 with $100 \%$ yield (Scheme 1). Compound 2 was finally isolated as its sodium salt using a cation exchange resin. The linking of COSAN derivative 3 to both perylene derivatives 4 and 5 produced an outstanding improvement of the solubility of these perylene dyes in polar organic solvents. For instance, they became significantly soluble in acetone (up to $360 \mathrm{mg}$ 
$\mathrm{mL}^{-1}$ for 2), while compounds $\mathbf{4}, \mathbf{5}$ and analogous bisalkylated PDI dye $\mathbf{7}$ (Scheme 1) are insoluble or poorly soluble in this solvent $\left(<1 \mathrm{mg} \mathrm{mL}^{-1}\right)$.

The structures of conjugates $\mathbf{1}$ and $\mathbf{2}$ were confirmed by IR-ATR, ${ }^{1} \mathrm{H},{ }^{13} \mathrm{C}\left\{{ }^{1} \mathrm{H}\right\}$ and ${ }^{11} \mathrm{~B}\left\{{ }^{1} \mathrm{H}\right\}$ NMR spectroscopy (see the Supporting Information), and MALDI-TOF mass spectrometry. The IR spectra for both compounds showed typical v(B-H) strong bands between 2533 and $2540 \mathrm{~cm}^{-1}$ settling the presence of boron clusters, while characteristic bands for the in-phase and out-of-phase stretching of cyclic imides were also observed at around 1650 and $1695 \mathrm{~cm}^{-1}$. Several ${ }^{1} \mathrm{H}$ NMR spectral features also demonstrated successful COSAN-PDI tethering in $\mathbf{1}$ and 2: (a) the downfield shift of the resonances for the $\mathrm{CH}_{2}$ protons from the oligooxyethylene chain of the COSAN fragment; (b) the presence of the aromatic signals of the PDI unit and, in the case of $\mathbf{1}$, of the resonances of its branched alkyl side chain at low frequencies. Similarly, the ${ }^{13} \mathrm{C}\left\{{ }^{1} \mathrm{H}\right\}$ NMR spectra of $\mathbf{1}$ and $\mathbf{2}$ showed resonances corresponding to their two different building blocks. Finally, the presence of boron clusters in these compounds was further confirmed by ${ }^{11} \mathrm{~B}\left\{{ }^{1} \mathrm{H}\right\}$ NMR spectroscopy. For dyad 1 that only contains one COSAN fragment, a 1:1:1:1:2:3:3:2:2:1:1 pattern in the typical range from $23.10(\mathrm{~B}-\mathrm{O})$ to $-28.67 \mathrm{ppm}$ was found in its ${ }^{11} \mathrm{~B}\left\{{ }^{1} \mathrm{H}\right\} \mathrm{NMR}$ spectrum; in the case of triad 2 comprising two COSAN groups, a 2:2:2:18:4:6:2 pattern with overlapped resonances in the range from 25.44 (B-O) to -26.77 was instead registered (see the Supporting Information).

\section{Electro-optical properties in solution}

The photophysical properties of dyad $\mathbf{1}$ and triad $\mathbf{2}$ in solution were investigated by UV-vis absorption and steady-state fluorescence spectroscopies at room temperature (Figure 2 and Table 1). The UV-vis absorption spectra of both compounds in acetonitrile showed the distinctive bands of each one of their constituting units (Figure 2a): the different vibronic bands in the visible region corresponding to the $S_{0}-S_{1}$ transition of the PDI fragment $\left(\lambda_{\mathrm{abs}, \max }=\right.$ 
$519 \mathrm{~nm})$, and the UV absorption band of the COSAN unit $\left(\lambda_{\mathrm{abs}, \max }=313 \mathrm{~nm}\right)$. Very minor spectral differences were observed relative to the absorbance of reference COSAN compound 3 and PDI dye 7 (Table 1), which proves that these moieties are not electronically coupled in the ground state of $\mathbf{1}$ and $\mathbf{2}$. As previously observed for other COSAN-containing conjugates, this could be mainly ascribed to the long separation distance between both fragments through the oligooxyethylene tether.
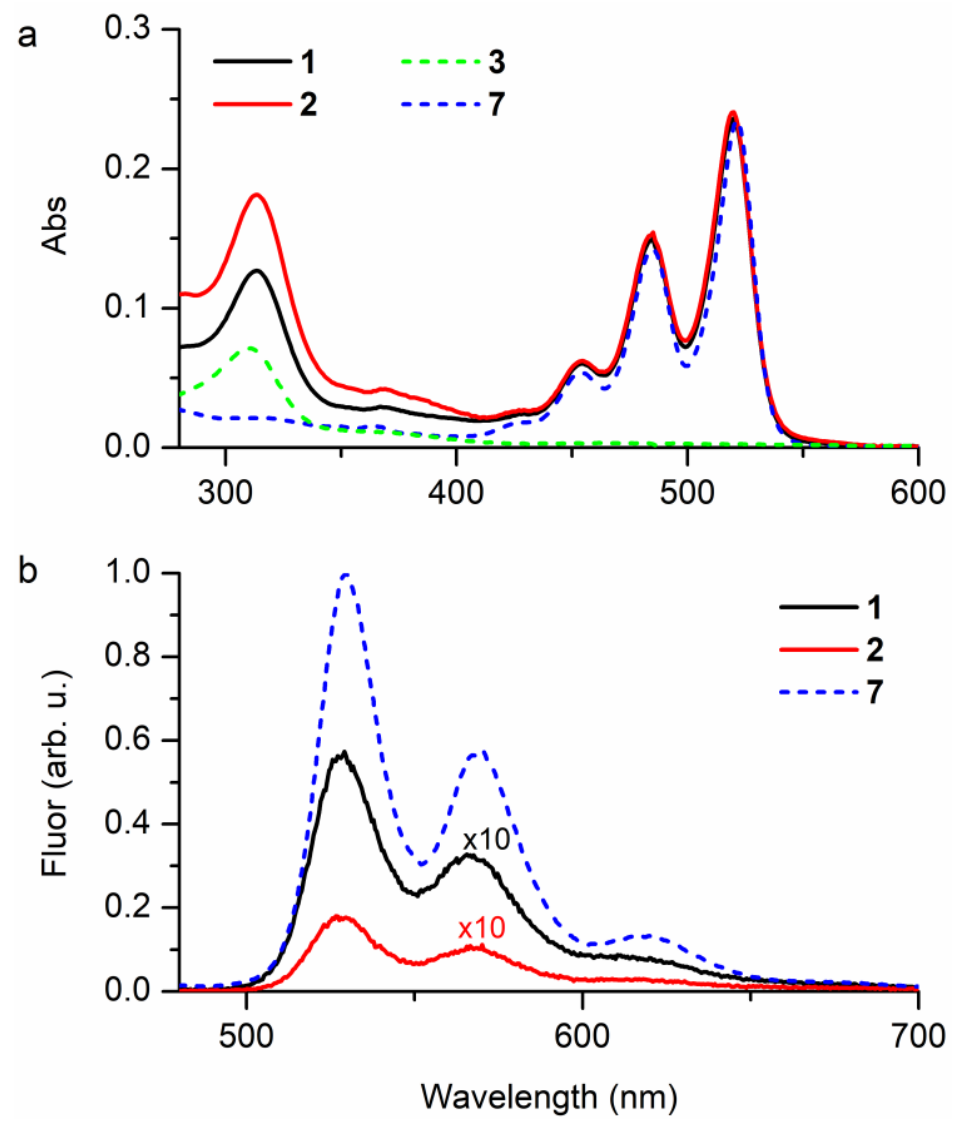

Figure 2. a) Absorption spectra of conjugates 1, 2 and reference compounds $\mathbf{3}$ and 7, in acetonitrile $\left(c \sim 3.010^{-6} \mathrm{M}\right)$. b) Fluorescence emission spectra of conjugates $\mathbf{1}$ and $\mathbf{2}$, and reference PDI compound 7 in acetonitrile $\left(c \sim 3.010^{-6} \mathrm{M}, \lambda_{\mathrm{exc}}=445 \mathrm{~nm}\right)$. For sake of clarity, the intensity of the spectra of $\mathbf{1}$ and $\mathbf{2}$ has been magnified (x10). 
Table 1. Electro-optical data of dyad 1, triad $\mathbf{2}$ and reference compounds $\mathbf{3}$ and $\mathbf{7 .}^{a}$

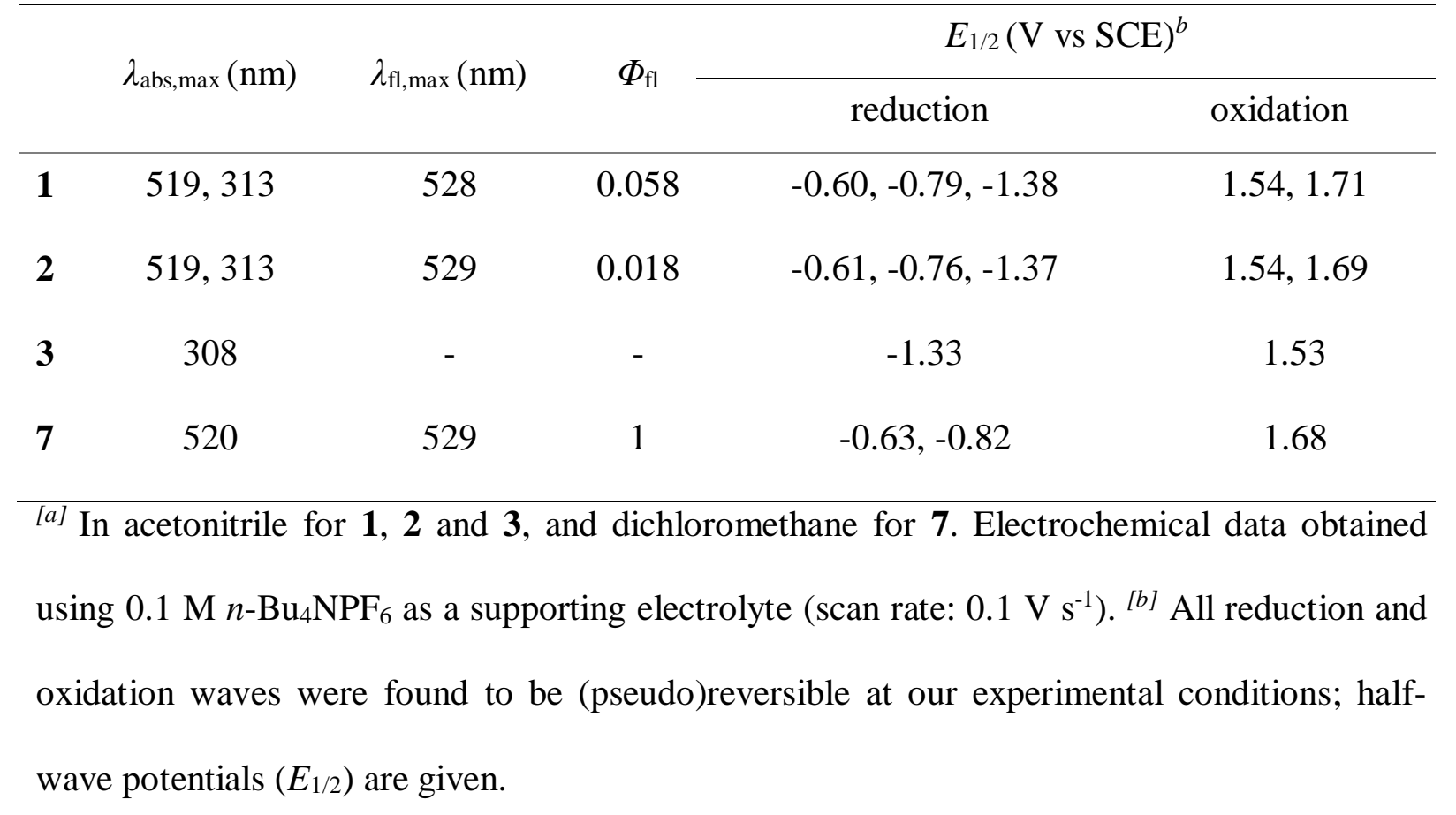

No significant spectral variations were observed either for the fluorescence emission of the PDI dye in 1 and 2 when compared to reference compound $7\left(\lambda_{\mathrm{fl}, \max } \sim 528 \mathrm{~nm}\right.$ in acetonitrile, Figure 2b). However, a dramatic decrement of emission intensity was registered, which became more pronounced for triad 2 bearing two COSAN clusters. Thus, while 7 presents a high fluorescence quantum yield typical for perylenediimide dyes $\left(\Phi_{\mathrm{fl}}=1\right.$ in acetonitrile $\left.^{[29]}\right)$, much lower values were determined for the COSAN-PDI conjugates $\left(\Phi_{\mathrm{fl}}=\right.$ 0.058 and 0.018 for $\mathbf{1}$ and $\mathbf{2}$ in acetonitrile, respectively). These results, which were replicated in other solvents (Table S1, Supporting Information), are a clear indication that the emission of these PDI-based fluorophores is strongly quenched by the nearby COSAN units, as previously observed for other emitters. ${ }^{[21 b, c]}$ Since there is no spectral overlap between PDI emission and COSAN absorption, this effect could not be ascribed to Förster resonance energy transfer (FRET) processes $^{[30]}$ between these two fragments. Instead, photoinduced electron transfer-induced quenching ${ }^{[30,31]}$ would be a much more plausible explanation given 
the rich electrochemical behavior of both $\operatorname{COSAN}^{[5 a]}$ and $\mathrm{PDI}^{[23 a]}$ moieties. This prompted us to investigate the redox properties of conjugates $\mathbf{1}$ and $\mathbf{2}$.

The cyclic voltammograms of $\mathbf{1}$ and $\mathbf{2}$ in acetonitrile displayed a large number of electrochemical waves that could be assigned to their different constituting units by comparison with the data registered for reference compounds $\mathbf{3}^{[5 \mathrm{a}]}$ and $\mathbf{7}^{[23 \mathrm{a}]}$ (Figure 3, Table 1 and Figure S1, Supporting Information). In the anodic region, two pseudoreversible waves were detected corresponding to the $\mathrm{Co}(\mathrm{III}) \rightarrow \mathrm{Co}(\mathrm{IV})$ oxidation of the metal center of the COSAN moiety $\left(E_{1 / 2}=+1.54 \mathrm{~V}\right.$ (vs SCE)), and the oxidation of the PDI fragment to its radical cation $\left(E_{1 / 2} \sim+1.70 \mathrm{~V}\right.$ (vs SCE)). A more complex behavior was encountered for the cathodic region, where reversible waves were detected for the consecutive, two-step reduction of the PDI unit to its dianion $\left(E_{1 / 2} \sim-0.60\right.$ and $-0.80 \mathrm{~V}$ (vs SCE)), and for the $\mathrm{Co}$ (III) $\rightarrow \mathrm{Co}$ (II) reduction of the COSAN metal cluster $\left(E_{1 / 2} \sim-1.47 \mathrm{~V}\right.$ (vs SCE)). Notably, minor differences were observed for the redox signals registered for $\mathbf{1}$ and $\mathbf{2}$ concerning reference compounds $\mathbf{3}$ and 7, which further evidence that the COSAN and PDI moieties are not electronically coupled in the conjugates. ${ }^{[32]}$

Based on the electro-optical properties determined for conjugates $\mathbf{1}$ and $\mathbf{2}$, the viability of photoinduced electron transfer (PET) processes under light irradiation that could quench the fluorescence of these compounds was evaluated using Rehm-Weller equation ${ }^{[31]}$ (Table S2, Supporting Information). Because of the distinct redox behavior of COSAN and PDI moieties, two different alternatives were explored: (a) PET from COSAN to PDI to produce the corresponding Co(IV) species and the perylenediimide radical anion; and (b) PET from PDI to COSAN to generate the perylenendiimide radical cation and the resulting Co(II) state of the metal cluster. While the latter was found not to be thermodynamically allowed ( $\Delta G_{\mathrm{PET}}$ $\sim+0.60 \mathrm{eV}$ for both $\mathbf{1}$ and $\mathbf{2}$ in acetonitrile), negative $\Delta G_{\text {PET }}$ values were obtained for the photoinduced electron transfer process from COSAN to PDI in the conjugates $\left(\Delta G_{\mathrm{PET}}=-0.22\right.$ 
and $-0.23 \mathrm{eV}$ for $\mathbf{1}$ and $\mathbf{2}$ in acetonitrile, respectively). As such, charge separation is expected to occur in these compounds after light absorption by their PDI unit, thus offering a competing, nonradiative pathway for excited state relaxation and, as experimentally proven, resulting in a striking loss of fluorescence emission. Interestingly, previous oxidation of the COSAN cluster to the Co(IV) state should prevent this PET-induced quenching mechanism, thereby opening the door for external modulation of the emission of $\mathbf{1}$ and $\mathbf{2}$ through redox stimuli.
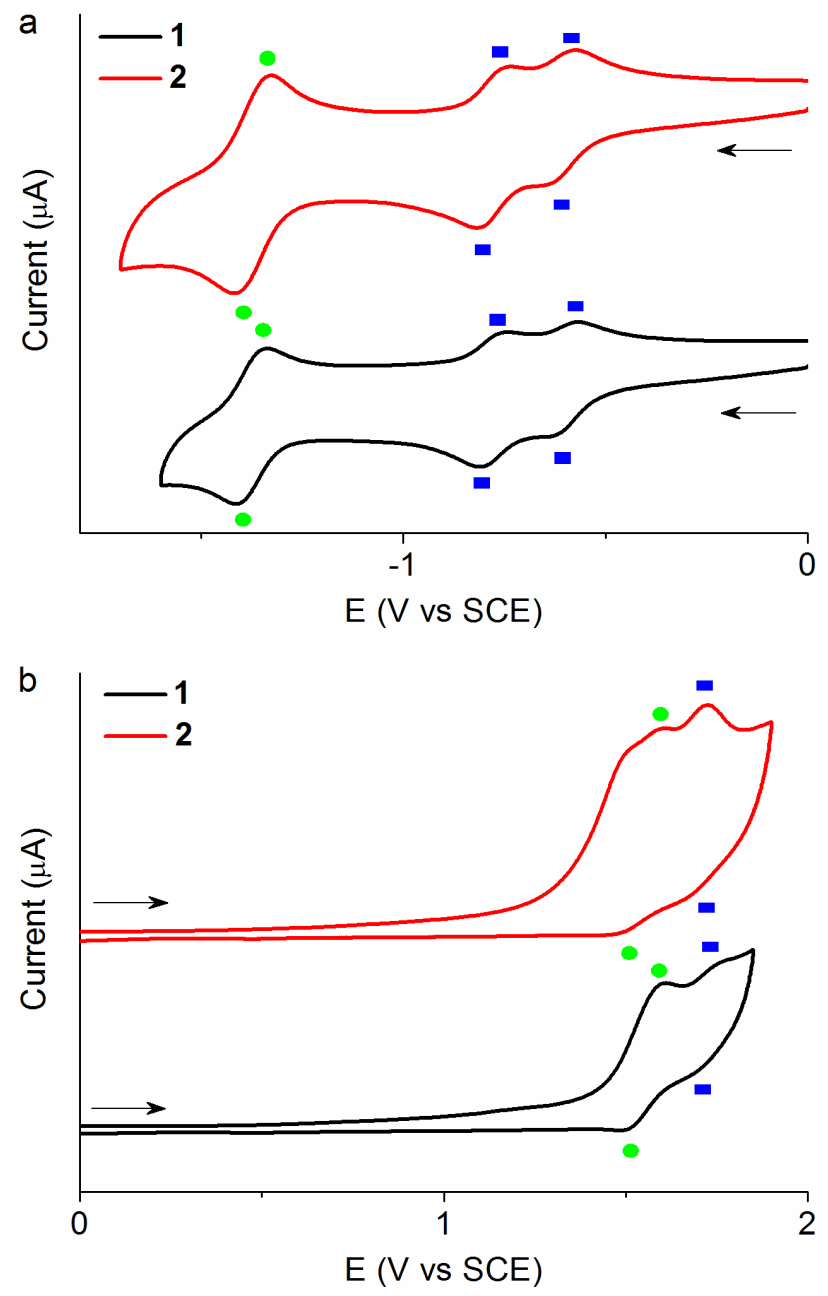

Figure 3. a) Cyclic voltammograms in reduction of conjugates $\mathbf{1}$ and $\mathbf{2}$ in acetonitrile $+0.1 \mathrm{M}$ $n$-Bu $\mathrm{NPF}_{6}\left(c \sim 0.510^{-3} \mathrm{M}\right.$, scan rate: $\left.0.1 \mathrm{~V} \mathrm{~s}^{-1}\right)$. b) Cyclic voltammograms in oxidation of conjugates 1 and 2 in acetonitrile $+0.1 \mathrm{M} n-\mathrm{Bu}_{4} \mathrm{NPF}_{6}\left(c \sim 1.010^{-3} \mathrm{M}\right.$, scan rate: $\left.0.3 \mathrm{~V} \mathrm{~s}^{-1}\right)$. 
Green circles and blue squares are used to assign the electrochemical waves arising from the COSAN and PDI units of these compounds, respectively. The arrows indicate the direction of the potential scan in each case.

\section{Fluorescence switching in solution}

To investigate the redox-induced fluorescence switching of conjugates $\mathbf{1}$ and $\mathbf{2}$ in solution, spectrofluoroelectrochemical experiments were conducted under $\mathrm{N}_{2}$ atmosphere. In this way, changes in the emission intensity could be measured for these compounds while applying sequential redox potentials to (a) oxidize their COSAN units to their Co(IV) state to inhibit fluorescence quenching by PET; and (b) reduce back the cobalt center from the boron clusters to the initial $\mathrm{Co}(\mathrm{III})$ state, which should lead to a concomitant decrease in emission.

For the first of these steps, careful selection of the experimental conditions was required to avoid simultaneous PDI $\rightarrow$ PDI $^{\bullet+}$ oxidation, which takes place at slightly larger potentials than the $\mathrm{Co}(\mathrm{III}) \rightarrow \mathrm{Co}(\mathrm{IV})$ transformation (see Figure 3). After several tests, we decided to apply a constant potential $\left(E_{\mathrm{app}}\right)$ at $+1.55 \mathrm{~V}$ (vs SCE) for both compounds until no further changes in fluorescence were registered (typically, for about 120 - $180 \mathrm{~s}$ ). It must be noted that no oxidation of the PDI unit took place under such conditions, as proven by the negligible absorption changes observed for this fluorophore in spectroelectrochemical measurements (Figure S2, Supporting Information). By contrast, a clear increase in emission intensity was simultaneously registered for both conjugates, which we attributed to COSAN oxidation and inhibition of PET-induced quenching of PDI fluorescence (Figure 4a). In particular, about 3and 5-fold increments in emission intensity were measured for $\mathbf{1}$ and $\mathbf{2}$ after application of $E_{\text {app }}=+1.50 \mathrm{~V}$ (vs SCE), which correspond to relative fluorescence enhancement percentages $(\Delta F)$ of $\Delta F=+258 \%$ and $+436 \%$, respectively. Larger $\Delta F$ values would, however, have been expected if the intrinsic emissive behavior of PDI in the conjugates had been fully restored 
upon oxidation of the COSAN moieties, given the very low $\Phi_{\mathrm{fl}}$ values of these compounds in the absence of electrochemical stimuli. Two different factors could account for this behavior: (a) incomplete electrochemical transformation of all the conjugate molecules in the optical path after saturation of the platinum gauze that we used as a working electrode in our spectrofluoroelectrochemical experiments; and (b) partial quenching of the fluorescence of the PDI unit of the compounds by the nearby oxidized metallacarborane clusters, which could in principle take place by reverse photoinduced electron transfer (i.e. from the fluorophore to the COSAN moieties in the Co(IV) state). Nevertheless, this did not prevent us from attaining strong modulation of the luminescence of $\mathbf{1}$ and $\mathbf{2}$ by oxidizing their COSAN units.

a
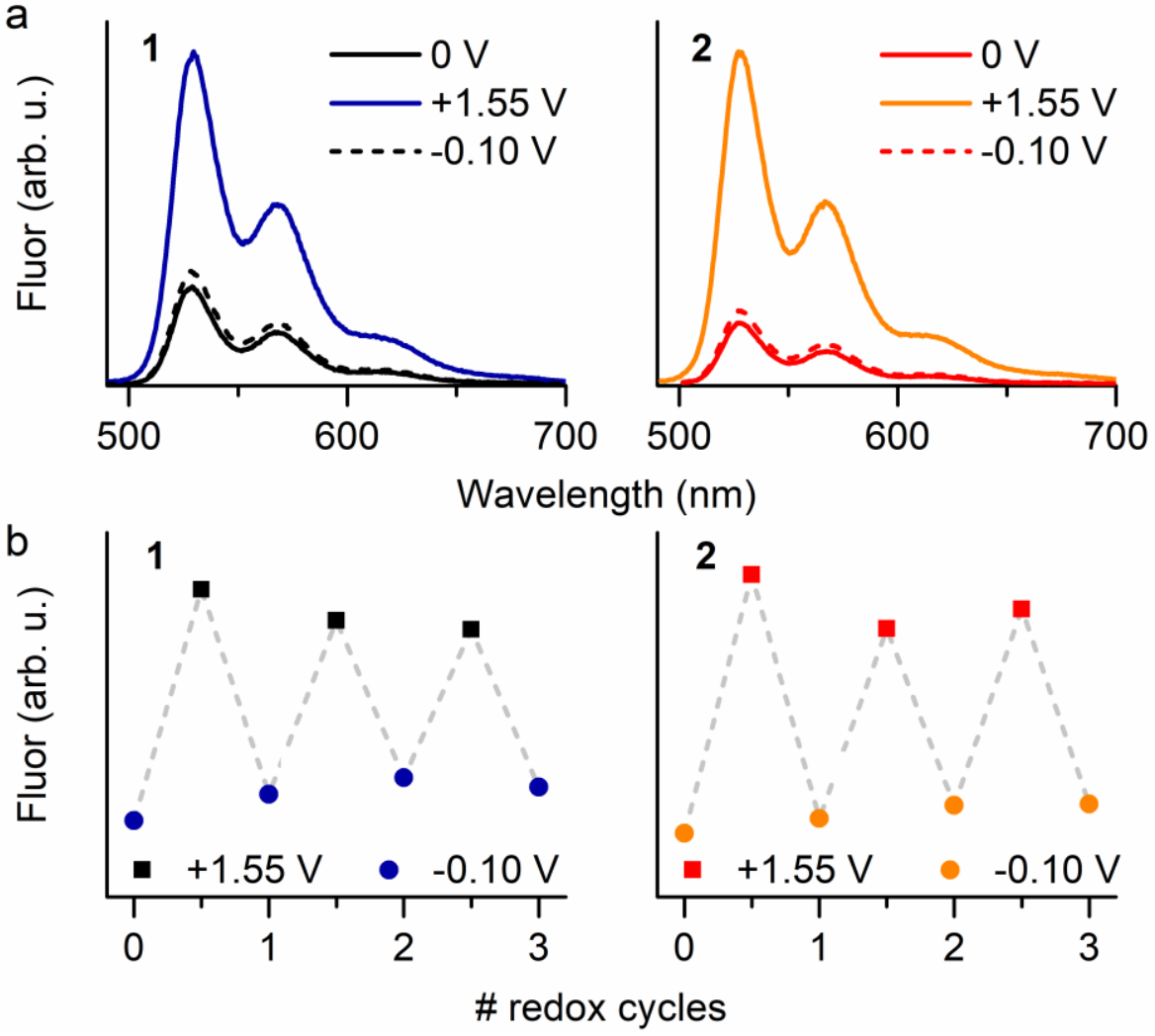

Figure 4. a) Variation of the fluorescence emission spectra of conjugates $\mathbf{1}$ and $\mathbf{2}$ upon consecutive controlled potential electrolysis at $+1.55 \mathrm{~V}$ and -0.10 (vs SCE) in acetonitrile + $0.1 \mathrm{M} n-\mathrm{Bu}_{4} \mathrm{NPF}_{6}\left(c \sim 2.0 \times 10^{-4} \mathrm{M}, \lambda_{\mathrm{exc}}=445 \mathrm{~nm}\right)$. b) Variation of the fluorescence emission 
intensity of $\mathbf{1}$ and $\mathbf{2}$ upon application of four consecutive redox cycles in acetonitrile $+0.1 \mathrm{M}$ $n-\mathrm{Bu}_{4} \mathrm{NPF}_{6}\left(c \sim 2.0 \times 10^{-4} \mathrm{M}, \lambda_{\mathrm{exc}}=445 \mathrm{~nm}\right)$.

Once proven oxidation-induced enhancement of the emission of $\mathbf{1}$ and $\mathbf{2}$, we explored the reversibility of this process by reducing back the COSAN moiety of these compounds while monitoring their fluorescence response. For this, we applied $E_{\text {app }}=-0.1 \mathrm{~V}$ until negligible changes in emission intensity were observed, which typically required about $120-180 \mathrm{~s}$. At these conditions, the Co(IV) state of the metallacarborane becomes unstable and should selectively convert into its $\mathrm{Co}$ (III) state, as further reduction of the metal ion or even of the PDI unit must occur at larger potentials (see Figure 3). This was confirmed by spectroelectrochemical measurements at $E_{\text {app }}=-0.1 \mathrm{~V}$, where neither variation of the absorption of the PDI fluorophore nor appearance of the typical spectral bands arising from its radical anion ${ }^{[29]}$ were observed (Figure S3, Supporting Information). Instead, a drop of the emission of the conjugates $\mathbf{1}$ and $\mathbf{2}$ was concomitantly registered until the fluorescence intensity of the starting conjugates was essentially regained (Figure $4 \mathrm{a}$ ). This was attributed to the back-transformation of the oxidized COSAN moieties to their original Co(III) state, thereby reactivating the fluorescence quenching mechanism proceeding through photoinduced electron transfer from the metallacarborane units to the PDI fluorophore.

To demonstrate the robustness and reproducibility of the emission modulation of $\mathbf{1}$ and $\mathbf{2}$ triggered by electrochemical stimuli, spectrofluoroelectrochemical measurements were performed for acetonitrile solutions of the conjugates when applied to up to 3 consecutive oxidation-reduction cycles (Figure $4 b$ ). Although these experiments were conducted under an inert atmosphere, similar results were obtained in air. In all the cases, reversible fluorescence modulation was observed in these experiments with minimal degradation, which indicates that all the charge-separated transient species generated electro- and photochemically for $\mathbf{1}$ and $\mathbf{2}$ present good stability even at ambient conditions. More importantly, this unambiguously 
demonstrates the capacity of compounds $\mathbf{1}$ and $\mathbf{2}$ to behave as redox-induced fluorescent switches, ${ }^{[33]}$ which could be of use for the design of molecular memories and information processing devices, ${ }^{[34]}$ biosensing and imaging probes,${ }^{[35]}$ or electrofluorochromic displays. ${ }^{[36]}$

To our understanding, this is the first example where such phenomenon has been achieved by using metallacarboranes as redox-active species, which allowed us surpassing previous reports based on the use of other metal complexes, mostly ferrocene ${ }^{[36]}$ (e.g. PDIferrocene conjugates $\left.{ }^{[33 a, 37]}\right)$. With respect to these precedents, compounds $\mathbf{1}$ and $\mathbf{2}$ present several advantages as redox-controlled fluorescent switches that arise from the particular properties of COSAN. On one hand, larger electrochemically-induced fluorescence modulation amplitudes were accomplished herein, which for triad $\mathbf{2}$ are at least 2 -fold greater than those previously reported. ${ }^{[33 a, 37]}$ In addition, such improved emission switching behavior was obtained even at larger emitter-quencher distances, since the use of very short methylene tethers was required to observe optimal fluorescence modulation in the case of PDI-ferrocene conjugates. $^{[33 a, 37]}$ As such, this demonstrates the potential of COSAN to show stronger electronic coupling effects with nearby organic fluorophores. This, in combination with its ability to undergo both oxidation and reduction processes at relatively low potentials, makes COSAN an ideal candidate for the realization of electrochemically-triggered fluorescent switches with both electron-deficient (e.g., PDI) and electron-rich emitters. On the other hand, compounds $\mathbf{1}$ and $\mathbf{2}$ developed in this work also benefit from the increment in solubility that COSAN provides in polar solvents, ${ }^{[16]}$ a much desired property for highly hydrophobic perylenediimides. $^{[38]}$ Finally, by exploiting the self-assembly capacity of COSAN, the emissive properties of their conjugates with fluorophores could be transferred and even enhanced in the solid state. 


\section{Optical properties in the solid-state}

Given the previous reports on the improved emissive behavior of carborane-fluorophore conjugates upon aggregation, ${ }^{[7,8 c-j]}$ we also investigated the optical properties of $\mathbf{1}$ and $\mathbf{2}$ in the solid state, which were compared to those of reference PDI dye 7. As previously reported for thin films of symmetric perylenediimide fluorophores bearing branched alkyl side chains, ${ }^{[39]}$ large differences were observed when optically characterizing $\mathbf{7}$ as a solid powder relative to solution. Thus, broader absorption covering most of the visible range (i.e. 400-600 nm) and drastically red-shifted emission $\left(\lambda_{\mathrm{fl}, \max }=653 \mathrm{~nm}\right)$ were measured, none of which showed the clear vibronic features registered for this compound in organic solvents (Figure S4, Supporting Information). These changes arise from the interchromophoric interactions that take place in the solid-state after molecular close-packing, which is mainly driven by co-facial $\pi$-stacking of the perylendiimide cores. ${ }^{[23 a]}$ As such, it must lead to the formation of excitonic $\mathrm{H}$-aggregates with hypsochromically-shifted absorption and negligible emission. ${ }^{[23 a, 40]}$ However, because of the steric hindrance introduced by the branched alkyl chains of $\mathbf{7}$, geometrically distorted columnar stacks with rotational displacement between neighbouring PDI units are expected to be obtained in this case, which ultimately alters the optical properties of aggregates. ${ }^{[39,41]}$ In particular, this makes the optical transition into their lower energy exciton state partially allowed, ${ }^{[39,41]}$ thus accounting for the longer-wavelength absorption component observed for $\mathbf{7}$ in the solid-state with respect to solution. As for the broad, bathochromically-shifted fluorescence registered, it is generally attributed to exciton relaxation into excimer sites formed along the $\pi$-stacks of PDI chromophores, which are typically weakly emissive. ${ }^{[39]}$ In fact, when measuring the fluorescence quantum yield of the solid powder of 7, a 6-fold decrement in $\Phi_{\mathrm{fl}}$ was determined $\left(\Phi_{\mathrm{fl}}=0.17\right)$ with respect to solution. 
Owing to the strong dependence of the optical properties of perylendiimide aggregates on the molecular arrangement, ${ }^{[23 a, 39]}$ we did not directly investigate the behavior of $\mathbf{1}$ and $\mathbf{2}$ as solid powders. Instead, we attempted to favor supramolecular order by conducting the structuration of both compounds using the slow solvent-induced precipitation method (or bulk solution-phase transfer method) in acetone-hexane mixtures. ${ }^{[42]}$ As shown in Figure 5a-b, this led to the formation of gel-like materials for $\mathbf{1}$ and $\mathbf{2}$, a situation that has already been reported for other amphiphilic PDI derivatives, ${ }^{[23 a, 43]}$ but has been seldom described for COSAN-based compounds. ${ }^{[44]}$ Inspection of these materials by scanning electron microscopy revealed that their solid phase was formed by micrometer-long 1D nanostructures of different morphologies: bundles of fibers of about $75 \mathrm{~nm}$ in diameter in the case of $\mathbf{1}$, and nanobelts with a rectangular cross-section of about $550 \times 50 \mathrm{~nm}$ for 2 , which should originate from the self-assembly of these compounds (Figure 5c-d). This was confirmed by X-ray powder diffraction of the dried gels, for which two main diffraction peaks were observed at very similar $2 \theta$ values that are indicative of supramolecular ordering (ca. $4.5^{\circ}$ and $25.4^{\circ}$; Figure S5, Supporting Information). On one hand, the reflections at around $25.4^{\circ}$ correspond to the $d$ spacings of $0.35 \mathrm{~nm}$ expected between adjacent co-facially $\pi$-stacked PDI units (e.g., as in the solid powder of 7, Figure 5c-d). ${ }^{[41 \mathrm{a}, \mathrm{b}]}$ As for the diffractions at about $4.5^{\circ}$, they can be assigned to the intercolumnar spacings between neighbouring stacks in the self-assembled nanostructures, ${ }^{[39 a, 41 a, b]}$ which are of 1.96 and $1.88 \mathrm{~nm}$ for $\mathbf{1}$ and $\mathbf{2}$, respectively. It must be noted that such $d$ values are considerably shorter than the long intramolecular axis of these compounds, which we estimated to be around 2.82 (1) and $3.89 \mathrm{~nm}$ (2) from molecular mechanics calculation at the MM2 level. This behavior is normally attributed to geometrical distortion of the columnar stacks of PDI chromophores (e.g., by rotational displacement of adjacent units), ${ }^{[39,41]}$ which was expected to occur in this case due to: (a) the electrostatic (and steric) repulsion between the negatively-charged COSAN side clusters of $\mathbf{1}$ and 2; and (b) the 
steric congestion caused by the branched alkyl chain of $\mathbf{1}$ (Figure 5c-d). Actually, because of the diverse nature of these interactions governing the mutual orientation of the pending side groups of $\mathbf{1}$ and $\mathbf{2}$ in adjacent stacked molecules, different supramolecular arrangements should take place in the nanostructures of these compounds, thus ultimately accounting for the distinct morphologies obtained. ${ }^{[42 b]}$

a

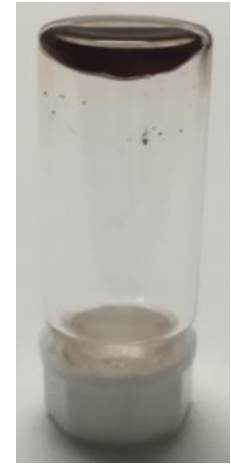

b

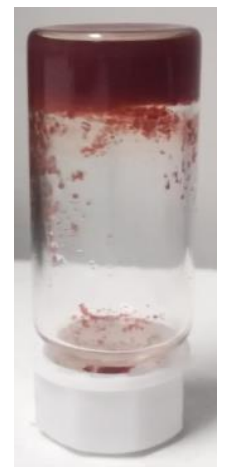

C

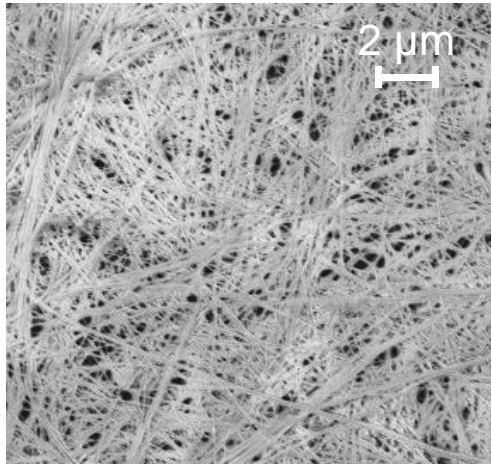

d

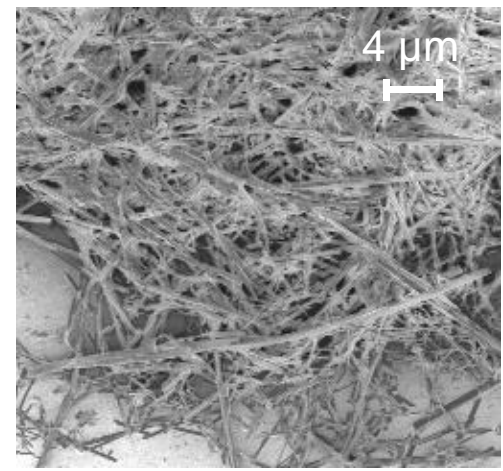

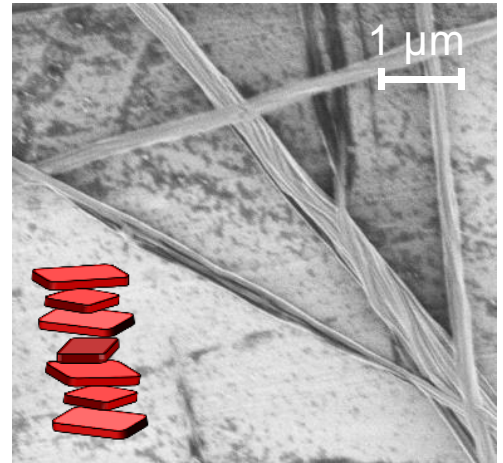

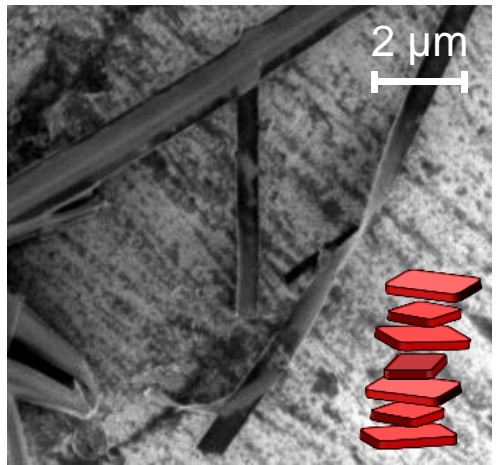

Figure 5. a-b) Photographs of the organogels obtained for a) 1 and b) 2. c-d) SEM images of the dried gels for c) $\mathbf{1}$ and d) $\mathbf{2}$. The insets in the SEM images show a schematic representation of the intracolumnar packing of the PDI units of $\mathbf{1}$ and $\mathbf{2}$, which are separated by a $d$-spacing of $0.35 \mathrm{~nm}$ and displaced with respect to each other to minimize the electrosteric repulsion between adjacent side groups.

Figure 6 shows the diffuse-reflectance absorption spectra of the gels obtained for compounds $\mathbf{1}$ and $\mathbf{2}$. In both cases, broad and poorly structured spectra were obtained, which are compatible with the optical behavior expected for these materials according to the 
molecular arrangement of their PDI units. As previously discussed for the solid powder of 7, the geometrical distortion of the co-facial stacks of PDI chromophores in the nanostructures of 1 and $\mathbf{2}$ must enable the optical transitions to the lowest exciton state of the aggregates formed, thus accounting for the longer-wavelength absorption component registered relative to the measurements in solution. Noticeably, such a component was found to be more prominent for the gel of $\mathbf{1}$, which corroborates that the $\pi$-stacked PDI units must be differently arranged in both materials due to their distinct side chains. This should not only affect their absorption properties but also their emissive behavior, as corroborated experimentally (Figure 6). On one hand, the gel obtained from 2 was observed to produce red-shifted and broad fluorescence with extremely low efficiency $\left(\lambda_{\mathrm{fl}, \max }=701 \mathrm{~nm}, \Phi_{\mathrm{fl}}=0.003\right)$ that cannot solely be explained based on the PET-induced quenching observed in solution. As such, the formation of a diversity of very poorly emissive excimers within the aggregates of $\pi$-stacked molecules is expected for this compound. By contrast, much stronger and narrower redshifted luminescence was registered for the gel 1, which fairly preserved the fluorescence quantum yield measured for this compound in organic solutions $\left(\lambda_{\mathrm{fl}, \max }=673 \mathrm{~nm}, \Phi_{\mathrm{fl}}=0.024\right)$ and was visible by the naked eye (see inset in Figure 6). Therefore, supramolecular ordering induced the creation of more defined and efficient emissive sites in this case upon aggregation, thus allowing the preparation of fluorescent gels for $\mathbf{1}$ despite the occurrence of PET between PDI and COSAN units. 
a

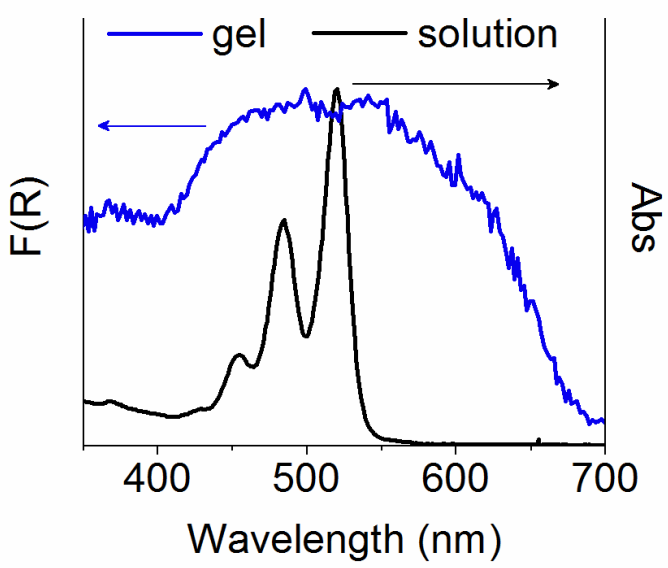

b

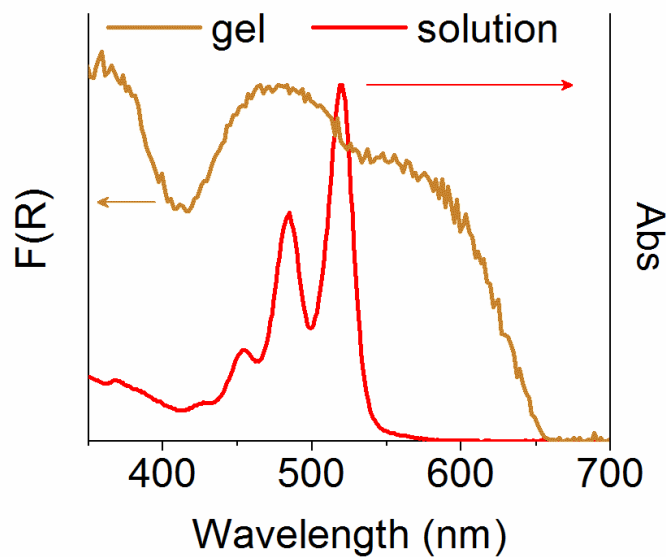

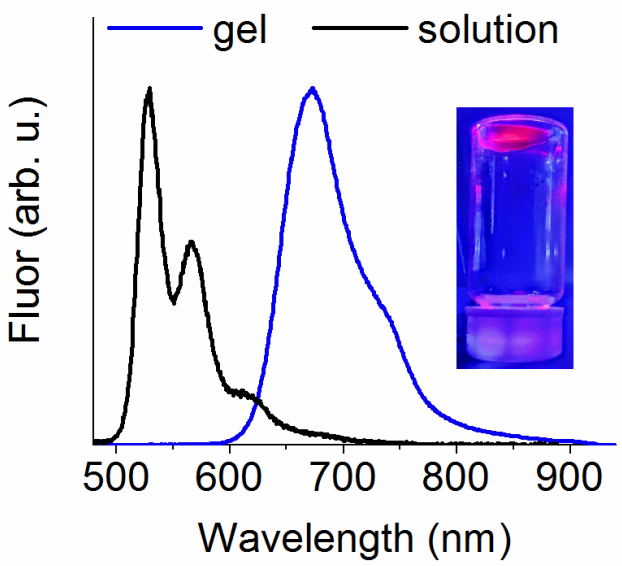

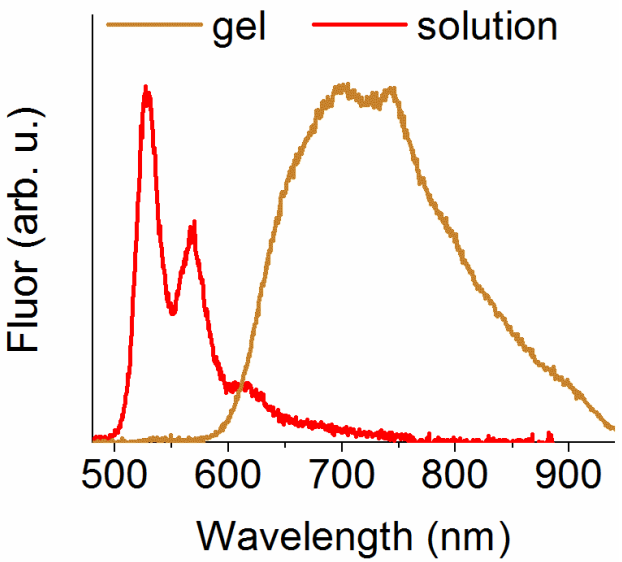

Figure 6. Absorption and emission $\left(\lambda_{\mathrm{exc}}=445 \mathrm{~nm}\right)$ spectra of the organogels obtained from a) 1 and b) 2, which are compared to those measured in acetonitrile solution for both compounds. In the case of gels absorbance, the Kubelka-Munk function $(F(R))$ determined from the diffuse reflectance absorption spectrum is given, as indicated by the arrows. For sake of comparison, all the spectra are normalized to unity at their maxima in the visible region. The inset in a) shows a photograph of the emission from the gel made from $\mathbf{1}$ under irradiation at $\lambda_{\mathrm{exc}}=445 \mathrm{~nm}$.

\section{Conclusions}

In this work, we reported the synthesis and characterization of two different metallacarboraneemitter conjugates: a dyad and a triad of cobaltabisdicarbollide (COSAN) and a perylendiimide dye (PDI), which were linked through a short oligooxyethylene linker. This, 
together with the particular redox properties of the metallacarborane and chromophore units, enabled photoinduced electron transfer to take place between them, which resulted in dramatic fluorescence quenching for both compounds. However, oxidation of the cobalt center of the COSAN moiety inhibited this process and enhanced the emission from the dyad and the triad, a situation that could be subsequently reverted upon reduction of the metallacarborane. As a result, we proved these systems to behave as redox-controlled fluorescent molecular switches in solution, which constitutes the first example of this type of smart behavior obtained from carboranes and metallacarboranes. For our COSAN-PDI dyad and triad, several advantages were found over precedent systems based on PDI conjugates with other metal complexes such as ferrocene. On one hand, they display larger fluorescence modulation at even longer emitter-quencher distances, while their solubility in polar media is dramatically enhanced. In addition, when treated with appropriate mixtures of organic solvents, the compounds prepared were observed to self-assemble into 1D nanostructures of different morphologies, which eventually gave rise to the formation of gel-like materials. In the case of the COSAN-perylendiimide dyad, strong red-shifted luminescence was observed for the gel, a result that we ascribed to the supramolecular arrangement achieved in the solid network of the material. Overall, we demonstrated that the optical properties of perylendiimide emitters can be tuned by appending nearby cobaltacarboranes, thus allowing access to new molecules and materials with improved functionalities that could find application in diverse areas (e.g., biosensing and imaging, fluorescent displays and photovoltaic devices).

\section{Experimental Section}

\section{Instrumentation}

ATR-IR spectra were recorded on JASCO FT/IR-4700 spectrometer on a high-resolution. The

${ }^{1} \mathrm{H}$ NMR (300.13 MHz), ${ }^{11} \mathrm{~B}\left\{{ }^{1} \mathrm{H}\right\}(96.29 \mathrm{MHz})$ and ${ }^{13} \mathrm{C}\left\{{ }^{1} \mathrm{H}\right\} \mathrm{NMR}(75.47 \mathrm{MHz}) \mathrm{NMR}$ spectra 
were recorded on a Bruker ARX 300 spectrometer. All NMR spectra were recorded in $\mathrm{CD}_{3} \mathrm{COCD}_{3}$ solutions at $25^{\circ} \mathrm{C}$. Chemical shift values for ${ }^{11} \mathrm{~B}\left\{{ }^{1} \mathrm{H}\right\}$ NMR spectra were referenced to external $\mathrm{BF}_{3} \cdot \mathrm{OEt}_{2}$, and those for ${ }^{1} \mathrm{H}$ and ${ }^{13} \mathrm{C}\left\{{ }^{1} \mathrm{H}\right\}$ NMR were referenced to $\mathrm{SiMe}_{4}$ (TMS). Chemical shifts are reported in units of parts per million downfield from the reference, and all coupling constants are reported in Hertz. MALDI-TOF-MS mass spectra were recorded in the negative ion mode using a Bruker Biflex MALDI-TOF $\left[\mathrm{N}_{2}\right.$ laser; $\lambda_{\mathrm{exc}}=$ $337 \mathrm{~nm}(0.5 \mathrm{~ns}$ pulses); voltage ion source $20.00 \mathrm{kV}$ (Uis1) and $17.50 \mathrm{kV}$ (Uis2)]. XRD experiments for the solid powder of 7 were performed with a X'Pert Powder diffractometer (Panalytical) with theta-theta geometry, copper anode X-ray tube and PIXcel ${ }^{1 \mathrm{D}}$ detector in a silicon crystal sample holder. In the case of the gels obtained from $\mathbf{1}$ and $\mathbf{2}$, XRD experiments were conducted in a Malvern PANalytical X'pert PRO MPD powder diffractometer with a vertical theta-theta goniometer (240 mm radius). These XRD analyses were carried out in transmission mode using a capillary spinner and the sample was filled inside borosilicate glass capillaries with an outer diameter of $0.7 \mathrm{~mm}$. A focusing mirror was used for the incident beam and a lineal $\mathrm{X}^{\prime}$ Celerator detector for the diffracted beam. In all the cases, the X-ray source was a ceramic X-ray tube with $\mathrm{Cu} K_{\alpha}$ anode $(\lambda=1.5406 \AA$ ). UV-Vis spectra in solution were recorded in a HP 8452A spectrophotometer (Agilent) with Chemstation software, using $1 \mathrm{~cm}$ cuvettes. When measuring solid samples, an Agilent Cary 60 spectrophotometer in diffuse reflectance mode and coupled to a remote integrating sphere was used. In this case, the Kubelka-Munk function was used to estimate their absorption spectra. Fluorescence emission spectra were recorded utilizing a custom-made spectrofluorometer, where the sample was excited with a cw laser (BeamQ, $\left.\lambda_{\mathrm{exc}}=440 \mathrm{~nm}\right)$ and emitted photons were detected using an Andor ICCD camera coupled to a spectrograph. All the emission spectra registered were corrected by the wavelength dependence of the spectral response of the detection system. Samples were prepared in spectroscopic grade solvents and adjusted to a response within the 
linear range. Fluorescence quantum yields in solution were determined using the standard method $^{[30]}$ for highly diluted solutions of the compounds of interest to prevent self-absorption processes (absorption $<0.1$ at the excitation wavelength) and relative to $N, N^{\prime}$-bis(1hexylheptyl)perylene-3,4,9,10-tetracarboxybismide in acetonitrile $\left(\Phi_{\mathrm{fl}}=1\right) .{ }^{[29]}$ For the solid samples, an absolute quantum yield spectrophotometer from Hamamatsu (model C9920-02G) was used, which is based on a wide spectrum $150 \mathrm{~W}$ Xenon light source coupled to a motorized monochromator, an integrating sphere equipped with a sample holder for solids, and a CCD spectrometer (Photonic multichanel analyzer PMA-12). Cyclic voltammograms were registered using a CHI 660 potentiostat and a conical electrochemical cell equipped with an argon bubbling source for degassing, a glassy carbon working electrode (WE, $d=0.45$ $\mathrm{mm})$, a glassy carbon auxiliary electrode $(\mathrm{CE}, \mathrm{d}=3 \mathrm{~mm})$ and a saturated calomel reference electrode (SCE, RE). All the potentials are reported versus an SCE isolated from the working electrode by a salt bridge. All measurements were performed in an acetonitrile solution containing $0.1 \mathrm{M}$ of $n-\mathrm{Bu}_{4} \mathrm{NPF}_{6}$ as a supporting electrolyte. Spectroelectrochemical and fluorospectroelectrochemical experiments were performed in a $1 \mathrm{~mm}$ thin layer quartz glass cell using platinum gauze and platinum wire as working and counterelectrodes, respectively, whereas a saturated calomel electrode (SCE) was used as a reference electrode. A PCcontrolled VSP-Potentiostat synchronized with an MMS-UV-vis high-speed diode array spectrometer with a bandwidth of 330-1100 nm and a deuterium/tungsten light source (HM) and optical fibre (SMA, J\&M) was employed to register the spectroelectrochemical measurements. Each absorption spectrum was recorded after 0.05 s. For fluorospectroelechemical measurements, the CHI 660 potentiostat and custom-made spectrofluorometer described above were used. In both cases, samples were typically degassed by bubbling $\mathrm{N}_{2}$ before conducting the measurements. 


\section{Materials}

All reactions were performed under an atmosphere of dinitrogen/argon employing standard Schlenk techniques. Commercial grade ethanol, diethyl ether, chloroform, acetonitrile and acetone were used without further purification. Compounds $4^{[26]}$ and $6^{[27]}$ were synthesized according to the literature. Perylene-3,4,9,10-tetracarboxylic dianhydride (5) and imidazole were purchased from Aldrich. $\mathrm{HCl}$ (37\% AGR ISO) was obtained from Labkem. $\mathrm{NH}_{3} 30 \%$ and cation exchange resin strongly acidic PA were acquired from Panreac.

Synthesis of 3. 10 eq. of $30 \% \mathrm{NH}_{3}$ was added dropwise to a solution of 6 (300 $\mathrm{mg}, 0.731$ mmol) in $96 \% \mathrm{EtOH}(7 \mathrm{~mL})$. The mixture was stirred and refluxed at $80^{\circ} \mathrm{C}$ for $48 \mathrm{~h}$, after which the solvent was removed under vacuum and the mixture was quenched with $\mathrm{HCl}(1 \mathrm{M}$, $10 \mathrm{~mL})$, transferred to a separating funnel, and extracted with $\mathrm{Et}_{2} \mathrm{O}(3 \times 10 \mathrm{~mL})$. The organic layer was extracted one time more with brine, then dried with $\mathrm{MgSO}_{4}$, and the volatile substances were finally removed under vacuum. The residue was treated with a mixture of cold $\mathrm{EtOH} / \mathrm{H}_{2} \mathrm{O}(10: 1)$ to obtain 3 as a yellow solid $\left(220 \mathrm{mg}, 70 \%\right.$ yield). ${ }^{1} \mathrm{H}$ NMR (300 MHz, acetone- $\left.d_{6}\right): \delta=7.89\left(\right.$ broad s, $\left.3 \mathrm{H} ; \mathrm{NH}_{3}\right), 4.07\left(\mathrm{~s}, 2 \mathrm{H} ; \mathrm{C}_{\mathrm{c}}-H\right), 3.98\left(\mathrm{~s}, 2 \mathrm{H} ; \mathrm{OCH}_{2}\right), 3.92\left(\mathrm{t},{ }^{3} J_{\mathrm{H}, \mathrm{H}}\right.$ $\left.=5.25 \mathrm{~Hz}, 2 \mathrm{H} ; \mathrm{OCH}_{2}\right), 3.78\left(\mathrm{~s}, 2 \mathrm{H} ; \mathrm{C}_{\mathrm{c}}-H\right), 3.68\left(\mathrm{t},{ }^{3} J_{\mathrm{H}, \mathrm{H}}=4 \mathrm{~Hz}, 2 \mathrm{H} ; \mathrm{OCH}_{2}\right), 3.53-3.46(\mathrm{~m}$, $\left.2 \mathrm{H} ; \mathrm{CH}_{2}-\mathrm{NH}_{2}\right) .{ }^{11} \mathrm{~B}\left\{{ }^{1} \mathrm{H}\right\}$ NMR $\left(96 \mathrm{MHz}\right.$, acetone- $\left.d_{6}\right): \delta=25.81(\mathrm{~s}, 1 \mathrm{~B}, B-\mathrm{O}), 8.11(\mathrm{~s}, 1 \mathrm{~B}, B-$ H), 1.89 (s, 1B, B-H), -1.27 (s, 1B, B-H), -3.84 (s, 1B, B-H), -5.35 (s, 4B, $B-\mathrm{H}),-7.92$ (s, 3B, $B-\mathrm{H}),-15.95(\mathrm{~s}, 2 \mathrm{~B}, B-\mathrm{H}),-18.97$ (s, 2B, $B-\mathrm{H}),-21.12(\mathrm{~s}, 1 \mathrm{~B}, B-\mathrm{H}),-27.55(\mathrm{~s}, 1 \mathrm{~B}, B-$ H). ${ }^{13} \mathrm{C}\left\{{ }^{1} \mathrm{H}\right\}$ NMR $\left(75 \mathrm{MHz}\right.$, acetone- $\left.d_{6}\right): \delta=40.19\left(\mathrm{~s}, C_{\mathrm{H}}-\mathrm{NH}_{3}\right), 46.81\left(\mathrm{~s} ; C_{\mathrm{c}}-\mathrm{H}\right), 51.66(\mathrm{~s} ;$ $\left.C_{\mathrm{c}}-\mathrm{H}\right), 66.30\left(\mathrm{~s} ; \mathrm{O}-\mathrm{CH}_{2}\right), 69.30\left(\mathrm{~s}, \mathrm{O}-\mathrm{CH}_{2}\right), 71.35\left(\mathrm{~s} ; \mathrm{O}-\mathrm{CH}_{2}\right) ; \operatorname{ATR}-\mathrm{IR}\left(\mathrm{cm}^{-1}\right): v=1597$ $(\mathrm{C}=\mathrm{C}), 2529(\mathrm{~B}-\mathrm{H}), 2871,2919\left(\mathrm{C}_{\mathrm{ar}} \mathrm{H}\right), 3040\left(\mathrm{C}_{\mathrm{c}}-\mathrm{H}\right), 2337\left(\mathrm{NH}_{3}\right)$.

Synthesis of 1. A mixture of $102 \mathrm{mg}(0.23 \mathrm{mmol})$ of $\mathbf{3}, 127 \mathrm{mg}(0.23 \mathrm{mmol})$ of $\mathrm{N}-(1-$ hexylheptyl)perylene-3,4:9,10-tetracarboxyl-3,4-anhidride-9,10-imide (4) and $5 \mathrm{~g}$ of imidazole were heated at $120{ }^{\circ} \mathrm{C}$ and stirred overnight under argon atmosphere. Then, the 
crude was cooled at room temperature and acidified until $\mathrm{pH}=2$ by adding aqueous $\mathrm{HCl}$ ( 2 M). After stirring overnight, the red solid obtained was filtered, washed with abundant distilled water, dried under vacuum at $120^{\circ} \mathrm{C}$ for $3 \mathrm{~h}$ and washed twice with $30 \mathrm{~mL}$ of diethyl ether to obtain $0.200 \mathrm{~g}(0.20 \mathrm{mmol}, 92 \%$ yield $)$ of the neutral protonated form of $\mathbf{1}$. This compound was then purified by recrystallization in acetone:hexane. For optical and electrochemical characterization experiments, a small fraction of this solid was further purified by preparative TLC using $\mathrm{CHCl}_{3}$ /acetone $10: 1$ as the eluent. ${ }^{1} \mathrm{H}$ NMR (400 $\mathrm{MHz}$, acetone- $\left.d_{6}\right): \delta=8.52-8.41\left(\mathrm{~m}, 4 \mathrm{H} ; \mathrm{C}_{6} H_{2}\right), 8.38\left(\mathrm{~d},{ }^{3} J_{\mathrm{H}, \mathrm{H}}=7.2 \mathrm{~Hz}, 2 \mathrm{H} ; \mathrm{C}_{6} H_{2}\right), 8.28\left(\mathrm{~d},{ }^{3} J_{\mathrm{H}, \mathrm{H}}=\right.$ $\left.7.2 \mathrm{~Hz}, 2 \mathrm{H} ; \mathrm{C}_{6} H_{2}\right), 5.26(\mathrm{~m}, 1 \mathrm{H} ; \mathrm{N}-\mathrm{CH}), 4.37\left(\mathrm{~m}, 2 \mathrm{H} ; \mathrm{C}_{\mathrm{c}}-H\right), 4.30-4.20\left(\mathrm{~m}, 4 \mathrm{H} ; \mathrm{OCH}_{2}\right.$ and $\left.\mathrm{C}_{\mathrm{c}}-\mathrm{H}\right), 3.88\left(\mathrm{~m}, 2 \mathrm{H} ; \mathrm{OCH}_{2}\right), 3.71\left(\mathrm{~m}, 4 \mathrm{H} ; \mathrm{CH}_{2}-\mathrm{NH}_{2}\right.$ and $\left.\mathrm{C}_{\mathrm{c}}-\mathrm{H}\right), 2.40\left(\mathrm{~m}, 2 \mathrm{H} ; \mathrm{CH}-\mathrm{CH}_{2}\right), 1.99$ (m, 2H; CH-CH$), 1.46\left(\mathrm{~m}, 8 \mathrm{H} ; \mathrm{C}_{4} H_{8}\right), 1.35\left(\mathrm{~m}, 8 \mathrm{H} ; \mathrm{C}_{4} H_{8}\right), 0.91\left(\mathrm{~m}, 6 \mathrm{H} ; \mathrm{CH}_{3}\right) .1 .00-3.00$ (Broad signal corresponding to B-H). ${ }^{11} \mathrm{~B}\left\{{ }^{1} \mathrm{H}\right\}$ NMR (128 MHz, acetone- $\left.d_{6}\right)$ : $\delta=23.10$ (s, 1B, $B-\mathrm{O}), 4.03$ (s, 1B, $B-\mathrm{H}), 0.39(\mathrm{~s}, 1 \mathrm{~B}, B-\mathrm{H}),-2.56(\mathrm{~s}, 1 \mathrm{~B}, B-\mathrm{H}),-4.57$ (s, 2B, $B-\mathrm{H}),-7.35$ (s, $3 \mathrm{~B}, B-\mathrm{H}),-8.16(\mathrm{~s}, 3 \mathrm{~B}, B-\mathrm{H}),-17.39(\mathrm{~s}, 2 \mathrm{~B}, B-\mathrm{H}),-20.35(\mathrm{~s}, 2 \mathrm{~B}, B-\mathrm{H}),-22.38(\mathrm{~s}, 1 \mathrm{~B}, B-$ $\mathrm{H}),-28.67(\mathrm{~s}, 1 \mathrm{~B}, B-\mathrm{H}) .{ }^{13} \mathrm{C}\left\{{ }^{1} \mathrm{H}\right\} \mathrm{NMR}\left(75 \mathrm{MHz}\right.$, acetone- $\left.d_{6}\right): \delta=13.15\left(\mathrm{~s}, C \mathrm{H}_{3}\right), 22.45(\mathrm{~s}$, $\left.C_{5} \mathrm{H}_{10}\right), 26.85$ (s, $\left.C_{5} \mathrm{H}_{10}\right), 29.57\left(\mathrm{~s}, C_{5} \mathrm{H}_{10}\right), 31.68\left(\mathrm{~s}, C_{5} \mathrm{H}_{10}, 32.24\left(\mathrm{~s}, C_{5} \mathrm{H}_{10}\right), 39.18\left(\mathrm{~s}, C_{\mathrm{H}_{2}-}\right.\right.$ N), $54.04(\mathrm{~s} ; C H-\mathrm{N}), 54.30\left(\mathrm{~s} ; C_{\mathrm{c}}-\mathrm{H}\right), 67.68\left(\mathrm{~s} ; \mathrm{O}-C_{2}\right), 68.59\left(\mathrm{~s}, \mathrm{O}-C_{2}\right), 71.55(\mathrm{~s} ; \mathrm{O}-$ $\left.\mathrm{CH}_{2}\right), 121.15\left(\mathrm{~s} ; C_{6} \mathrm{H}_{2}\right), 123.29\left(\mathrm{~s} ; C_{6} \mathrm{H}_{2}\right), 130.51\left(\mathrm{~s} ; C_{6} \mathrm{H}_{2}\right), 133.73\left(\mathrm{~s} ; C_{6} \mathrm{H}_{2}\right), 162.71(\mathrm{~s}$; $C=\mathrm{O})$; ATR-IR $\left(\mathrm{cm}^{-1}\right): v=1592(\mathrm{C}=\mathrm{C}), 1650,1693(\mathrm{C}=\mathrm{O}), 2540(\mathrm{~B}-\mathrm{H}), 2869,2922\left(\mathrm{C}_{\mathrm{ar}} \mathrm{H}\right)$, $3042\left(\mathrm{C}_{\mathrm{c}^{-}} \mathrm{H}\right)$; MALDI-TOF-MS: m/z calcd for [4]- 982.53 ; found: 982.14.

Synthesis of 2. A mixture of $61 \mathrm{mg}(0.14 \mathrm{mmol})$ of $\mathbf{3}, 23 \mathrm{mg}(0.059 \mathrm{mmol})$ of commercially available perylene-3,4,9,10-tetracarboxylic dianhydride (5) and $5 \mathrm{~g}$ of imidazole were heated at $120^{\circ} \mathrm{C}$ under argon atmosphere and stirred overnight. Upon reaction completion, the mixture was cooled at room temperature and aqueous $\mathrm{HCl}(2 \mathrm{M})$ was added to acidify the crude until $\mathrm{pH}=2$. After stirring overnight, the suspension was filtered under vacuum and 
washed with abundant distilled water. The red solid obtained was dried under vacuum at 120 ${ }^{\circ} \mathrm{C}$ for $3 \mathrm{~h}$ and then washed twice with $20 \mathrm{~mL}$ of diethyl ether to obtain $75 \mathrm{mg}$ (0.059 mmol, $100 \%$ yield) of 2 . This compound was then purified by recrystallization in acetone:hexane. ${ }^{1} \mathrm{H}$ NMR (400 MHz, acetone- $\left.d_{6}\right): \delta=9.17\left(\mathrm{~s}, 2 \mathrm{H}, H^{+}-\mathrm{COSAN}\right), 7.88\left(\mathrm{~d},{ }^{3} J_{\mathrm{H}, \mathrm{H}}=7.2 \mathrm{~Hz}, 2 \mathrm{H}\right.$; $\left.\mathrm{C}_{6} H_{2}\right), 7.80\left(\mathrm{~m}, 4 \mathrm{H}, \mathrm{C}_{6} H_{2}\right), 7.71\left(\mathrm{~m}, 2 \mathrm{H}, \mathrm{C}_{6} H_{2}\right), 4.22-4.13\left(\mathrm{~m}, 12 \mathrm{H} ; \mathrm{OCH}_{2}\right.$ and $\left.\mathrm{C}_{\mathrm{c}}-H\right), 3.92-$ $3.80\left(\mathrm{~m}, 12 \mathrm{H} ; \mathrm{OCH}_{2}, \mathrm{CH}_{2}-\mathrm{N}\right.$ and $\left.\mathrm{C}_{\mathrm{c}}-\mathrm{H}\right) \cdot 1.25-3.00$ (Broad signal corresponding to $\mathrm{B}-\mathrm{H}$ ) ${ }^{11} \mathrm{~B}\left\{{ }^{1} \mathrm{H}\right\}$ NMR $\left(128 \mathrm{MHz}\right.$, acetone- $\left.d_{6}\right): \delta=25.44$ (s, 2B, $\left.B-\mathrm{O}\right), 6.93$ (s, 2B, B-H), 1.72 (s, 2B, $B-\mathrm{H}),-5.57(\mathrm{~s}, 18 \mathrm{~B}, B-\mathrm{H}),-15.81(\mathrm{~s}, 4 \mathrm{~B}, B-\mathrm{H}),-19.06(\mathrm{~s}, 6 \mathrm{~B}, B-\mathrm{H}),-26.77(\mathrm{~s}, 2 \mathrm{~B}, B-\mathrm{H})$.

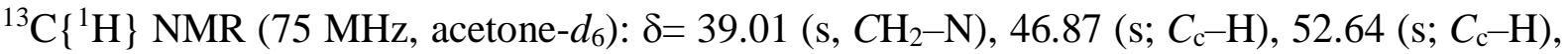
$67.42\left(\mathrm{~s} ; \mathrm{O}-\mathrm{CH}_{2}\right), 68.96\left(\mathrm{~s}, \mathrm{O}-\mathrm{CH}_{2}\right), 71.67\left(\mathrm{~s} ; \mathrm{O}-\mathrm{CH}_{2}\right), 122.76\left(\mathrm{~s} ; C_{6} \mathrm{H}_{2}\right), 124.05\left(\mathrm{~s} ; C_{6} \mathrm{H}_{2}\right)$, $127.40\left(\mathrm{~s} ; C_{6} \mathrm{H}_{2}\right), 129.99\left(\mathrm{~s} ; C_{6} \mathrm{H}_{2}\right), 132.55\left(\mathrm{~s} ; C_{6} \mathrm{H}_{2}\right), 134.80\left(\mathrm{~s} ; C_{6} \mathrm{H}_{2}\right), 162.18(\mathrm{~s} ; C=\mathrm{O})$; ATR-IR $\left(\mathrm{cm}^{-1}\right): v=1652,1693(\mathrm{C}=\mathrm{O}), 2533(\mathrm{~B}-\mathrm{H}), 2860,2923,2956\left(\mathrm{C}_{\mathrm{ar}} \mathrm{H}\right), 3049\left(\mathrm{C}_{\mathrm{c}}-\mathrm{H}\right)$. Compound 2 was dissolved in a minimum volume of acetonitrile/water (50:50). The solution was passed repeatedly through a cation exchanging resin, previously loaded with $\mathrm{NaCl}$. The solvent mixture was finally evaporated to give compound $\mathbf{N a} \mathbf{a}_{2}[2]$. This compound was then purified by recrystallization in acetone:hexane. For optical and electrochemical characterization experiments, a small fraction of this solid was further purified by preparative TLC using $\mathrm{CHCl}_{3} /$ acetone $10: 1$ as the eluent. ${ }^{1} \mathrm{H}$ NMR (300 MHz, acetone- $\left.d_{6}\right): \delta=8.00-7.77$ $\left(\mathrm{m}, 4 \mathrm{H} ; \mathrm{C}_{6} H_{2}\right), 7.75-7.40\left(\mathrm{~m}, 4 \mathrm{H} ; \mathrm{C}_{6} H_{2}\right), 4.40-4.17\left(\mathrm{~m}, 12 \mathrm{H} ; \mathrm{OCH}_{2}\right.$ and $\left.\mathrm{C}_{\mathrm{c}}-H\right), 4.00-3.70(\mathrm{~m}$, $12 \mathrm{H}$; $\mathrm{OCH}_{2}, \mathrm{CH}_{2}-\mathrm{N}$ and $\left.\mathrm{C}_{\mathrm{c}}-H\right)$. Broad signal corresponding to $\mathrm{B}-\mathrm{H}$ ? ${ }^{11} \mathrm{~B}\left\{{ }^{1} \mathrm{H}\right\}$ NMR (128 $\mathrm{MHz}$, acetone- $\left.d_{6}\right): \delta=25.39(\mathrm{~s}, 2 \mathrm{~B}, B-\mathrm{O}), 6.38(\mathrm{~s}, 2 \mathrm{~B}, B-\mathrm{H}), 1.75(\mathrm{~s}, 2 \mathrm{~B}, B-\mathrm{H}),-5.62(\mathrm{~s}$, 18B, $B-\mathrm{H}),-15.94(\mathrm{~s}, 4 \mathrm{~B}, B-\mathrm{H}),-18.97(\mathrm{~s}, 6 \mathrm{~B}, B-\mathrm{H}),-27.17(\mathrm{~s}, 2 \mathrm{~B}, B-\mathrm{H}) .{ }^{13} \mathrm{C}\left\{{ }^{1} \mathrm{H}\right\} \mathrm{NMR}$ $\left(75 \mathrm{MHz}\right.$, acetone- $\left.d_{6}\right): \delta=39.04\left(\mathrm{~s}, C_{2}-\mathrm{N}\right), 46.82\left(\mathrm{~s} ; C_{\mathrm{c}}-\mathrm{H}\right), 52.71\left(\mathrm{~s} ; C_{\mathrm{c}}-\mathrm{H}\right), 67.36(\mathrm{~s} ; \mathrm{O}-$ $\left.\mathrm{CH}_{2}\right), 68.88\left(\mathrm{~s}, \mathrm{O}-\mathrm{CH}_{2}\right), 71.72\left(\mathrm{~s} ; \mathrm{O}-\mathrm{CH}_{2}\right), 122.74\left(\mathrm{~s} ; C_{6} \mathrm{H}_{2}\right), 124.11\left(\mathrm{~s} ; C_{6} \mathrm{H}_{2}\right), 127.32(\mathrm{~s}$; $\left.C_{6} \mathrm{H}_{2}\right), 129.92\left(\mathrm{~s} ; C_{6} \mathrm{H}_{2}\right), 132.56\left(\mathrm{~s} ; C_{6} \mathrm{H}_{2}\right), 134.88\left(\mathrm{~s} ; C_{6} \mathrm{H}_{2}\right), 162.31(\mathrm{~s} ; C=\mathrm{O})$. 
Structuration of 1 and 2. First, $1 \mathrm{~mL}$ of a stock solution of the compound of interest in acetone $\left(c_{1}=2.0 \cdot 10^{-3} \mathrm{M}, c_{2}=2.4 \cdot 10^{-3} \mathrm{M}\right)$ was introduced in a test tube. Then, $1 \mathrm{~mL}$ of hexane was added dropwise without stirring and allowing drops to slide down the tube walls. After 30 minutes, $3 \mathrm{~mL}$ of hexane were added following the same procedure. The two phases formed are left to mix by diffusion overnight. The gel formed was separated from the liquid, and 4 $\mathrm{mL}$ of acetone/hexane (1:4) was added until no color was observed in the liquid.

\section{Acknowledgements}

This work was supported by MINECO/FEDER (CTQ2015-65439-R and CTQ2016-75150-R projects) and Generalitat de Catalunya (2017 SGR00465 and 2017 SGR1720 projects). ICMAB acknowledges the support of the Spanish MINECO through the Severo Ochoa Centers of Excellence Program, under grant SEV-2015-0496. L. P. thanks the Universitat Autònoma de Barcelona for her predoctoral PIF fellowship.

\section{References}

[1] a) R. N. Grimes, Carboranes, Academic Press, 2016. b) C. E. Housecroft, Boron: Metallacarbaboranes, Encyclopedia of Inorganic and Bioinorganic Chemistry, Wiley 2011. c) N. S. Hosmane, Boron Science: New Technologies and Applications, Taylor \& Francis, 2011.

[2] a) C. Viñas, E. Hey-Hawkins, Boron-Based Compounds: Potential and Emerging Applications in Medicine, Wiley, 2018. b) F. Issa, M. Kassiou, L. M. Rendina. Chem. Rev. 2011, 111, 5701-5722. c) C. Viñas, R. Núñez, I. Bennour, F. Teixidor. Current Med. Chem. 2019, 26, 5036-5076. d) M. Chaari, Z. Kelemen, D. Choquesillo-Lazarte, N. Gaztelumendi, F. Teixidor, C. Viñas, C. Nogués, R. Núñez, Biomater. Sci. 2019, 7, 5324- 
5337. e) C. Bellomo, M. Chaari, J. Cabrera-González, M. Blangetti, C. Lombardi, A. Deagostino, C. Viñas, N. Gaztelumendi, C. Nogués, R. Nuñez, C. Prandi, Chem. Eur. J. 2018, 24, 15622-15630.

[3] a) F. Teixidor, R. Nuñez, M. A. Flores, A. Demonceau, C. Viñas, J. Organomet. Chem. 2000, 614-615, 48-56. b) S. P. Fisher, A. W. Tomich, S. O. Lovera, J. F. Kleinasser, J. Guo, M. J. Asay, H. M. Nelson, V. Lavallo, Chem. Rev. 2019, 119, 8262-8290.

[4] a) B. P. Dash, R. Satapathy, J. A. Maguire, N. S. Hosmane, New. J. Chem. 2011, 35, 1955-1972. b) R. Núñez, I. Romero, F. Teixidor, C. Viñas, Chem. Soc. Rev. 2016, 45, $5147-5173$

[5] a) R. Núñez, M. Tarrès, A. Ferrer-Ugalde, F. F. de Biani, F. Teixidor, Chem. Rev. 2016, 116, 14307-14378. b) S. Mukherjee, P. Thilagar, Chem. Commun. 2016, 52, 1070-1093. c) J. Cabrera-González, A. Ferrer-Ugalde, S. Bhattacharyya, M. Chaari, F. Teixidor, J. Gierschner, R. Núñez, J. Mater. Chem. C 2017, 5, 10211-10219. d) M. Chaari, J. Cabrera-González, Z. Kelemen, C. Viñas, A. Ferrer-Ugalde, D. Choquesillo-Lazarte, A. Ben Salah, F. Teixidor, R. Núñez, J. Organomet. Chem. 2018, 865, 206-213.

[6] a) R. Ziessel, G. Ulrich, J. H. Olivier, T. Bura, A. Sutter, Chem. Commun. 2010, 46, 7978-7980. b) D. Hablot, A. Sutter, P. Retailleau, R. Ziessel, Chem. Eur. J. 2012, 18, 1890-1895. c) A. Harriman, M. A. H. Alamiry, J. P. Hagon, D. Hablot, R. Ziessel, Angew. Chem. Int. Ed. 2013, 52, 6611-6615. d) D. Hablot, R. Ziessel, M. A. H. Alamiry, E. Bahraidah, A. Harriman, Chem. Sci. 2013, 4, 444-453. e) A. V. Safronov, N. I. Shlyakhtina, T. A. Everett, M. R. VanGordon, Y. V. Sevryugina, S. S. Jalisatgi, M. F. Hawthorne, Inorg. Chem. 2014, 53, 10045-10053.

[7] a) K. Kokado, Y. Chujo, Macromolecules. 2009, 42, 1418-1420; b) J. Cabrera-González, C. Viñas, M. Haukka, S. Bhattacharyya, J. Gierschner, R. Núñez, Chem. Eur. J. 2016, 22, 13588-13598. c) M. Chaari, Z. Kelemen, J. G. Planas, F. Teixidor, D. Choquesillo- 
Lazarte, A. Ben Salah, C. Viñas, R. Núñez, J. Mater. Chem. C 2018, 6, 11336-11347. d) Y. Yin, X. Li, S. Yan, H. Yan, C. Lu, Chem. Asian J. 2018, 13, 3155-3159. e) X. Wei, M.-J. Zhu, Z. Cheng, M. Lee, H. Yan, C. Lu, J.J. Xu, Angew. Chem. Int. Ed. 2019, 58, 3162-3166; Angew. Chem. 2019, 131, 3194-3198.

[8] a) K. Kokado, Y. Chujo, J. Org. Chem. 2011, 76, 316-319. b) L. Weber, J. Kahlert, R. Brockhinke, L. Böhling, A. Brockhinke, H.-G. Stammler, B. Neumann, R. A. Harder, M. A. Fox, Chem. Eur. J. 2012, 18, 8347-8357. c) K. Nishino, H. Yamamoto, K. Tanaka, Y. Chujo, Org. Lett. 2016, 18, 4064-4067. d) R. Furue, T. Nishimoto, I. S. Park, J. Lee, T. Yasuda, Angew. Chem. Int. Ed. 2016, 55, 7171-7175; Angew. Chem. 2016, 128, 72877291. e) D. Tu, P. Leong, Z. Li, R. Hu, C. Shi, K. Y. Zhang, H. Yan, Q. A. Zhao, Chem. Commun. 2016, 52, 12494-12497. f) H. Naito, K. Nishino, Y. Morisaki, K. Tanaka, Y. Chujo, J. Mater. Chem. C 2017, 5, 10047-10054. g) X. Wu, J. Guo, Y. Quan, W. Jia, D. Jia, Y. Chen, Z. Xie, J. Mater. Chem. C 2018, 6, 4140-4149. h) N. V. Nghia, S. Jana, S. Sujith, J. Y. Ryu, J. Lee, S. U. Lee, M. H. Lee, Angew. Chem. Int. Ed. 2018, 57, 1248312488; Angew. Chem. 2018, 130, 12663-12668. i) K. L. Martin, J. N. Smith, E. R. Young, K. R. Carter, Macromolecules 2019, 52, 7951-7960. j) Y.-J. Cho, S.-Y. Kim, J.W. Lee, W.-S. Han, C. H. Kim, H.-J. Son, S. O. Kang, Chem. Eur. J. 2019, 25, 81498156.

[9] P. Farràs, E. J. Juárez-Pérez, M. Lepsik, R. Luque, R. Núñez, F. Teixidor, Chem. Soc. Rev. 2012, 41, 3445-3463.

[10] I. Guerrero, Z. Kelemen, C. Viñas, I. Romero, F. Teixidor, Chem. Eur. J. 2020, 26, 50275036.

[11] I. B. Sivaev, V. I. Bregadze, Collect. Czech. Chem. Commun. 1999, 64, 783-805.

[12] a) C. Masalles, S. Borrós, C. Viñas, F. Teixidor, Adv. Mater. 2000, 12, 1199-1202. b) C. Masalles, J. Llop, C. Viñas, F. Teixidor, Adv. Mater. 2002, 14, 826-829. 
[13] a) P. Matějíček, P. Cígler, K. Procházka, V. Král, Langmuir 2006, 22, 575-581. b) J. Rak, B. Dejlová, H. Lampová, R. Kaplánek, P. Matějíček, P. Cígler, V. Král, Mol. Pharm. 2013, 10, 1751-1759.

[14] a) P. Bauduin, S. Prevost, P. Farràs, F. Teixidor, O. Diat, T. A. Zemb, Angew. Chem. Int. Ed. 2011, 50, 5298-5300; Angew. Chem. 2011, 123, 5410-5412. b) D. Brusselle, P. Bauduin, L. Girard, A. Zaulet, C. Viñas, F. Teixidor, I. Ly, O. Diat, Angew. Chem. Int. Ed. 2013, 52, 12114-12118; Angew. Chem. 2013, 125, 12336-12340. c) P.-M. Gassin, L. Girard, G. Martin-Gassin, D. Brusselle, A. Jonchère, O. Diat, C. Viñas, F. Teixidor, P. Bauduin, Langmuir 2015, 31, 2297-2303. d) M. Uchman, V. Ďord’ovič, Z. Tošner, P. Matějíček, Angew. Chem. Int. Ed. 2015, 54, 14113-14117; Angew. Chem. Int. Ed. 2015, 127, 14319-14323. e) R. Fernández-Álvarez, V. Ďord’ovič, M. Uchman, P. Matějíček, Langmuir 2017, 34, 3541-3554.

[15] a) E. J. Juárez-Pérez, C. Viñas, F. Teixidor, R. Núñez, Organometallics 2009, 28, 55505559. b) R. Núñez, E. J. Juárez-Pérez, F. Teixidor, R. Santillan, N. Farfán, A. Abreu, R. Yépez, C. Viñas, Inorg. Chem. 2010, 49, 9993-10000. c) C. Viñas, F. Teixidor, R. Núñez, Inorg. Chim. Acta 2014, 409, 12-25.

[16] a) J. Cabrera-González, V. Sánchez-Arderiu, C. Viñas, T. Parella, F. Teixidor, R. Núñez, Inorg. Chem. 2016, 55, 11630-11634. b) J. Cabrera-González, M. Chaari, F. Teixidor, Clara Viñas, Rosario Núñez, Molecules 2020, 25, 1210.

[17]E. J. Juárez-Pérez, P. H. Mutin, M. Granier, F. Teixidor, R. Núñez, Langmuir 2010, 26, 12185-12189.

[18] V. Dordovic, M. Uchman, M. Reza, J. Ruokolainen, A. Zhigunov, O. I. Ivankov, P. Matejicek, RSC Adv. 2016, 6, 9884-9892.

[19]L. Cabana, A. González-Campo, X. Ke, G. Van Tendeloo, R. Núñez, G. Tobias, Chem. Eur. J. 2015, 21, 16792-16795. 
[20] J. Cabrera-González, L. Cabana, B. Ballesteros, G. Tobias, R. Núñez, Chem. Eur. J. 2016, 22, 5096-5101.

[21] a) E. J. Juárez-Pérez, C. Viñas, F. Teixidor, R. Santillan, N. Farfán, A. Abreu, R. Yépez, R. Núñez, Macromolecules 2010, 43, 150-159. b) M. Chaari, N. Gaztelumendi, J. Cabrera-González, P. Peixoto-Moledo, C. Viñas, E. Xochitiotzi-Flores, N. Farfán, A. Ben Salah, C. Nogués, R. Núñez, Bioconjugate Chem. 2018, 29, 1763-1773. c) J. CabreraGonzález, B. M. Muñoz Flores, C. Viñas, A. Chávez-Reyes, H. V. R. Dias, V. M. Jiménez Pérez, R. Nuñez, Chem. Eur. J. 2018, 24, 5601-5612.

[22] a) E. Hao, M. G. H. Vicente, Chem. Commun. 2005, 1306-1308. b) E. Hao, M. SibrianVázquez, W. Serem, J. C. Garno, F. R. Fronczek, M. G. H. Vicente, Chem. Eur. J. 2007, 13, 9035-9047. c) E. Hao, M. Zhang, E. Wenbo, K. M. Kadish, F. R. Froczeck, B. H. Courtney, M. G. H. Vicente, Bioconjugate Chem. 2008, 19, 2171-2181. d) H. Li, F. R. Fronczek, M. G. H. Vicente, Tetrahedron Lett. 2008, 49, 4828-4830. e) G. Y. Atmaca, C. Dizman, T. Eren, A. Erdogmus, Spectrochim. Acta, Part A, 2015, 137, 244-249. f) M. Uchman, P. Jurkiewicz, P. Cigler, B. Grüner, M. Hof, K. Procházka, P. Matejicek, Langmuir 2010, 26, 6268-6275.

[23] a) F. Würthner, Chem. Commun. 2004, 1564-1579. b) A. Nowak-Król, F. Würthner, Org. Chem. Frontiers 2019, 6, 1272-1318.

[24] a) C. Li, H. Wonneberger, Adv. Mater. 2012, 24, 613-636. b) F. Fernández-Lázaro, N. Zink-Lorre, A. Sastre-Santos, J. Mater. Chem. A 2016, 4, 9336-9346.

[25] a) S. Chen, P. Slattum, C. Wang, L. Zang, Chem. Rev. 2015, 115, 11967-11998. b) F. Würthner, C. R. Saha-Möller, B. Fimmel, S. Ogi, P. Leowanawat, D. Schmidt, Chem. Rev. 2016, 116, 962-1052.

[26] H. Kaiser, J. Lindner, H. Langhals Chem. Ber. 1991, 124, 529-535. 
[27]F. Teixidor, J. Pedrajas, I. Rojo, C. Viñas, R. Kivekäs, R. Sillanpää, I. Sivaev, V. Bregadze, S. Sjöberg, Organometallics 2003, 22, 3414-3423.

[28] a) A. Semioshkin, E. Nizhnik, I. Godovikov, Z. Starikova, V. Bregadze, J. Organomet. Chem. 2007, 692, 4020-4028. b) E. J. Juárez-Pérez, M. Granier, C. Viñas, P. H. Mutin, R. Núñez, Chem. Asian J. 2012, 7, 277-281.

[29] T. Kircher, H.-G. Löhmannsröben, Phys. Chem. Chem. Phys. 1999, 1, 3987-3992.

[30] J. R. Lakowicz, Principles of Fluorescence Spectroscopy, Springer: NewYork, 2006.

[31] M. Berberich, A. Krause, M. Orlandi, F. Scandola, F. Würthner, Angew. Chem. Int. Ed. 2008, 47, 6616-6619; Angew. Chem. 2008, 120, 6718-6721.

[32] A. B. Buades, V. Sánchez-Arderiu, D. Olid-Britos, C. Viñas, R. Sillanpää, M. Haukka, X. Fontrodona, M. Paradinas, C. Ocal, F. Teixidor, J. Am. Chem. Soc. 2018, 140, 29572970.

[33] a) R. Zhang, Z. Wang, Y. Wu, H. Fu, J. Yao, Org. Lett. 2008, 10, 3065-3068. b) M. Tropiano, N. Kilah, M. Morten, H. Rahman, J. J. David, P. D. Beer, S. Faulkner, J. Am. Chem. Soc. 2011, 133, 11847-11849. c) I. Gallardo, G. Guirado, J. Hernando, S. Morais, G. Prats, Chem. Sci. 2016, 7, 1819-1825.

[34] a) C. Simao, M. Mas-Torrent, N. Crivillers, V. Lloveras, J. M. Artés, P. Gorostiza, J. Veciana, C. Rovira, Nat. Chem. 2011, 3, 359-364; b) B. Daly, T. S. Moody, A. J. M. Huxley, C. Yao, B. Schazmann, A. Alves-Areias, J. F. Malone, N. Gunaratne, P. Nockemann, A. P. de Silva, Nat. Commun. 2019, 10, 49.

[35] a) J. Vogelsang, T. Cordes, C. Forthmann, C. Steinhauer, P. Tinnefeld, Proc. Natl. Acad. Sci. USA 2009, 106, 8107-8112. b) Z; Lou, P. Li, K. Han, Acc. Chem. Res. 2015, 48, $1358-1368$

[36] a) P. Audebert, F. Miomandre, Chem. Sci. 2013, 4, 575-584. b) J. Sun, Y. Chen, Z. Liang, Adv. Funct. Mater. 2016, 26, $2783-2799$. 
[37] R. Zhang, Y. Wu, Z. Wang, W. Xue, H. Fu, J. A. Yao, J. Phys. Chem. C 2009, 113, 25942602.

[38] M. Sun, K. Müllen, M. Yin, Chem. Soc. Rev. 2016, 45, 1513-1528.

[39] a) K. Balakrishnan, A. Datar, T. Naddo, J. Huang, R. Oitker, M. Yen, J. Zhao, L. Zang, J. Am. Chem. Soc. 2006, 128, 7390-7398. b) R. Matthews, J. Swisher, K. M. Hutchins, E. B. Pentzer, Chem. Mater. 2018, 30, 3571-3577. c) K. M. Felter, V. M. Caselli, D. D. Günbas, T. J. Savenije, F. C. Grozema, ACS Appl. Energy Mater. 2019, 2, 8010-8021.

[40] M. Kasha, H. R. Rawls, M. A. El-Bayoumi, Pure Appl. Chem. 1965, 11, 371-392.

[41] a) F. Nolde, W. Pisula, S. Müller, C. Kohl, K. Müllen, Chem. Mater. 2006, 18, 37153725. b) A. Wicklein, A. Lang, M. Muth, M. Thelakkat, J. Am. Chem. Soc. 2009, 131, 14442-14453. c) F. Würthner, T. E. Kaiser, C. R. Saha-Möller, Angew. Chem. Int. Ed. 2011, 50, 3376-3410; Angew. Chem. Int. Ed. 2011, 123, 3436-3473.

[42] a) R. C. Savage, J. M. Mativetsky, E. Orgiu, M. Palma, G. Gbabode, Y. H. Geerts, P. Samorì, J. Mater. Chem. 2011, 21, 206-213. b) S. Chen, P. Slattum, C. Wang, L. Zang, Chem. Rev. 2015, 115, 11967-11998.

[43] S. S. Babu, V. K. Praveen, A. Ajayaghosh, Chem. Rev. 2014, 114, 1973-2129.

[44] a) V. Dordovic, M. Uchman, K. Procházka, A. Zhigunov, J. Plestil, A. Nykänen, J. Ruokolainen, P. Metejicek, Macromolecules 2013, 46, 6881-6890. b) V. Dordovic, M. Uchman, A. Zhigunov, A. Nykänen, J. Ruokolainen, P. Metejicek, ACS Macro Lett. 2014, 3, 1151-1155. 


\section{Table of contents graphical abstract}

Novel redox-responsive fluorescence switches are developed based on

cobaltabisdicarbollide-perylenediimide conjugates, which are exploited for the preparation of luminescent gels.

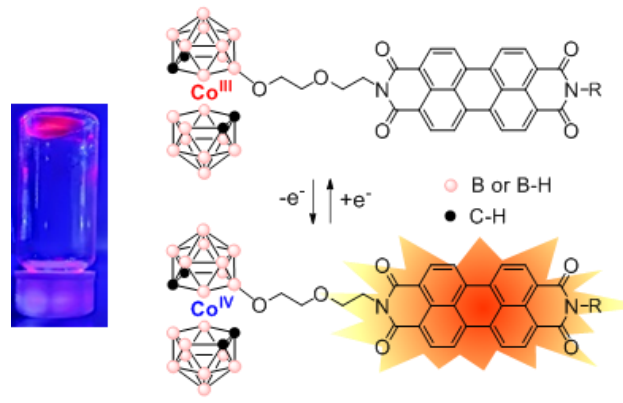

Keywords: fluorescent switches, metallacarborane, perylenediimide, redox centers, supramolecular gels 